\title{
Design and Analysis of Heptagonal Cladding With Rotated-Hexa Elliptical Core Based PCF for the Applications of Communication Sectors in the THz Region
}

Md. Selim Hossain

Daffodil International University

Shuvo Sen ( $\sim$ shuvombstu.it12009@gmail.com )

MBSTU

\section{Research Article}

Keywords: Scattering loss, Confinement loss, EML, PCF, Heptagonal Cladding, Terahertz Optical Fiber Posted Date: March 15th, 2021

DOI: https://doi.org/10.21203/rs.3.rs-278764/v1

License: (c) (i) This work is licensed under a Creative Commons Attribution 4.0 International License. Read Full License

Version of Record: A version of this preprint was published at Optical and Quantum Electronics on November 2nd, 2021. See the published version at https://doi.org/10.1007/s11082-021-03326-8. 


\title{
Design and Analysis of Heptagonal Cladding with Rotated-Hexa Elliptical Core Based PCF for the Applications of Communication Sectors in the THz Region
}

\author{
Md. Selim Hossain ${ }^{1}$, Shuvo Sen ${ }^{2 *}$ \\ ${ }^{1}$ Department of Computing and Information System, Daffodil International University (DIU), \\ Dhaka, Bangladesh \\ ${ }^{2}$ Department of Information and Communication Technology (ICT), Mawlana Bhashani Science \\ and Technology University (MBSTU), Santosh, Tangail-1902, Bangladesh \\ *Corresponding Author: Mawlana Bhashani Science and Technology University (MBSTU), \\ Santosh, Tangail-1902, Bangladesh \\ Email: shuvombstu.it12009@gmail.com
}

\begin{abstract}
Photonic crystal fiber (PCF) beside heptagonal cladding with elliptical rotated-hexa curved center are talked about for terahertz $(\mathrm{THz})$ waveguide. It is recognized that a successful effective material loss (EML) of $0.0076 \mathrm{~cm}-1$ has been accomplished at $1 \mathrm{THz}$ working recurrence. By utilizing the photonic crystal fiber PCF) concept, all reenactment comes about have been gotten with the limited finite element method (FEM) and perfectly match layer (PML) border conditions based on COMSOL Multiphysics computer apparatuses. This PCF fiber uncovers EML of $0.0076 \mathrm{~cm}-1$, with expansive an effective area (EA) of $5.95 \times 10-8 \mathrm{~m} 2$ and stream of control within the center locale of $90 \%$ at $1 \mathrm{THz}$. Besides, around pivotal optical directing viewpoints like as restriction misfortune, scattering, methodology, power fraction (PF) and effective mode area (EMA) have been too considered briefly. It is expected that the mentioned PCF waveguide will offer a significant improvement over existing design for communication field. Maintaining the typical principles for all the optical constraints suggests that the anticipated PCF can proficiently be pragmatic in multichannel communication and some other domains of the $\mathrm{THz}$ technology.
\end{abstract}

Index Terms - Scattering loss, Confinement loss, EML, PCF, Heptagonal Cladding, Terahertz Optical Fiber.

\section{Introduction}

Recently Terahertz (THz) radiation T-ray or spectrum which varies from 0.1 to $10 \mathrm{THz}$, has gained significant interest owing to its numerous practical applications. Tray area lies within the context of the infrared radiation (IR) and microwave spectrum. The enormous $\mathrm{THz}$ frequency is potential in diverse areas like sensing [1- 2], biomedical imaging [3], communications [4], 
biotechnology [5], time-domain spectroscopy [6], salinity [], temperature sensor [7], security screening [8] applications. It also provides significant developments in origins and identification methods of $\mathrm{THz}$ wave. The entire $\mathrm{THz}$ system consists of three distinct parts, they are the sources of THz, wave guidance, and sensor. Among of them THz source and sensor are available in commercially. The $\mathrm{THz}$ sources and sensors are rapidly upgraded with the support of advanced modern technology. The most significant kinds of $\mathrm{THz}$ sources are Gunn diodes, free electron lasers, quantum cascade lasers, organic gas far infrared laser etc. Besides, Bolometer, Golay Cell, Pyroelectric detector, Schottky barrier diodes are the most usable T-ray detector []. However, due to frequency propagation, most $\mathrm{THz}$ waveguides largely depends on the free-space wave propagation. But, the free space wave propagation faces some problems such as path loss, material loss and high absorption loss [9]. In order to minimize these problems, the researchers had already proposed various waveguides because of the successful propagation of the $\mathrm{THz}$ wave. These are Bragg fibers [13], Metallic waveguides [10], Silver coated hollow glass [11], subwavelength waveguide [15], parallel-plate waveguides [14] etc. Uses of metallic waveguides in THz transmission can face difficulties like high bending loss and frequency-dependent losses. Bragg fibers offer better efficiency in dispersion and filtering applications, but in the context of realistic wavelength division multiplexing (WDM) applications it is very difficult to obtain desirable output by using Bragg fibers. Parallel-plate waveguides main limitation is ohomic loss. In recently, microstructure core PCF (photonic crystal fiber) exhibits the advanced structural flexibility and extremely high optical properties. A significant advantage is that maximum optical power passes across the core region that helps to reduce material loss. Two basic optical guiding properties are commonly found in microstructure core PCF, one of them is modified total internal refection (MTIR) and the other is photonic band gap (PBG). When the cladding's refractive index (RI) is greater than the core RI, photonic bandgap function works in PCF. On the other side, when the core RI is larger than cladding, the MTIR impact comes into operation. In $\mathrm{THz}$ guiding medium, microstructure PCF is proposed to obtain lower confinement loss, highly numerical aperture (NA), lower dispersion, highly birefringence and better wave guiding properties. By using solid materials in the core region, PCF experiences high material loses. To reduce the material loss, porous air core is preferred across a solid core [16]. Such properties are helpful to utilize porous polymer PCFs as in different filtering and sensing applications. Different types of background materials such as Zeonex [17], TOPAS [18], Teflon [19], PMMA 
(Poly methyl methacrylate) [20], ZBLAN [21], Graphene [] are being used to increase the optical guiding properties and minimize the effective material loss (EML). We use Topas as the background materials because it exhibits some excellent optical properties such aslower material loss, high temperature insensitive, low dispersion and constant refractive index over the 0.1 to 2 $\mathrm{THz}$ frequency range [22]. The researchers mainly focus to reduce EML, scattering loss and maximizing the core power fraction in THz wave-based PCF. In 2012, Bao et al. [23], proposed porous-core honeycomb bandgap THz fibers which shows higher EML and coupling loss of 0.35 $\mathrm{cm}^{-1}$ and $5 \mathrm{~dB}$ respectively. Their proposed structure EML is very high. Later, Islam et al. [24] introduced a spiral shape PCF which achieved efficient area and EML is $1.82 \times 107 \mathrm{~m} 2$ and 0.10 $\mathrm{cm}-1$ accordingly at $1 \mathrm{THz}$ frequency range. Through their obtained EML is high and they did not show two important factor as V-parameter and power fraction. Moreover, Hasanuzzaman et al. [26] proposed kagome lattice structure PCF and decreased the EML to $0.035 \mathrm{~cm}^{-1}$ with a dispersion difference of $0.13955 \mathrm{ps} / \mathrm{THz} / \mathrm{cm}$. But their proposed structure is nearly difficult to fabricate. In that context, Saiful et al. [28] proposed a structure build in circular lattice with hexagonal core and achieved an EML of $0.047 \mathrm{~cm}^{-1}$ with dispersion variance $0.15 \mathrm{ps} / \mathrm{THz} / \mathrm{cm}$. J.Sultana et al. [29] proposed a zeonex based kagome structured cladding and hexagonal shaped core PCF with an EML of $0.04 \mathrm{~cm}-1$ and dispersion of $\pm 0.09 \mathrm{ps} / \mathrm{THz} / \mathrm{cm}$ at $1 \mathrm{THz}$. Very recently in 2020, Another mocrostructure PCF structures named THz wave propagation quasi-pattern was introduced by B. K. Paul et al. [30] their introduced model obtains EML of $0.038 \mathrm{~cm}-1$ with an optimum frequency of $1 \mathrm{THz}$. There is a large scope to design and modifying PCF sensor in $\mathrm{THz}$ frequency region to achieve best optical guidance properties.

In this article, we introduced $\mathrm{H}-\mathrm{PCF}$ for $\mathrm{THz}$ wave propagation to overcome such limitations of the previously proposed sensor [23-28]. TOPAS is used as the background material for our proposed model. The proposed H-PCF exhibits outstanding optical properties as well. The proposed model exhibits lower EML of $0.0076 \mathrm{~cm}^{-1}$ and gained maximum core power fraction of $90 \%$ at the frequency of $1 \mathrm{THz}$.

\section{Design Methodology}


The cross view of PCF is uncovered in Fig. 1 where $\mathrm{P}_{1}$ and $\mathrm{m}_{1}$ are characterized by the pitch and breadth of our plan concept. The limitations $d_{1} / A_{1}$ is called the discuss filling proportion and this proportion tries to watch against collapse between two AHs and the foundation fabric of TOPAS makes a difference to decrease numerous sorts of misfortunes. $A_{c}, d_{a}$ and $d_{b}$ limitations are called the pitch and breadths of the two circular AHs so also. At the elliptical rotated-hexa core territory, the first layer of 6 circular air holes contain a $20^{\circ}, 80^{\circ}, 140^{\circ}, 200^{\circ}, 260^{\circ}, 320^{\circ}$ angles and second layer of 12 circular air holes contain a $20^{\circ}, 50^{\circ}, 80^{\circ}, 110^{\circ}, 140^{\circ}, 170^{\circ}, 200^{\circ}, 230^{\circ}$, $260^{\circ}, 290^{\circ}, 320^{\circ}, 350^{\circ}$. Here, we discover the numerical properties such as successful zone, diffusing misfortune, V-parameter, EML, fiber control division, and confinement loss of the fiber within the $\mathrm{THz}$ locale with the COMSOL Multiphysics software. The ideal imperatives are cladding distance across $\mathrm{d}_{1}=\mathrm{d}_{2}=\mathrm{d}_{3}=\mathrm{d}_{4}=\mathrm{d}_{5}=299 \mu \mathrm{m}$, cladding pitch $\mathrm{A}_{1}=\mathrm{A}_{2}=\mathrm{A}_{3}=\mathrm{A}_{4}=\mathrm{A}_{5}$ $=355 \mu \mathrm{m}$, center distance across $\mathrm{d}_{\mathrm{a}}=54 \mu \mathrm{m}, \mathrm{d}_{\mathrm{b}}=56 \mu \mathrm{m}$ and center pitch $\mathrm{A}_{\mathrm{c}}=60 \mu \mathrm{m}$.

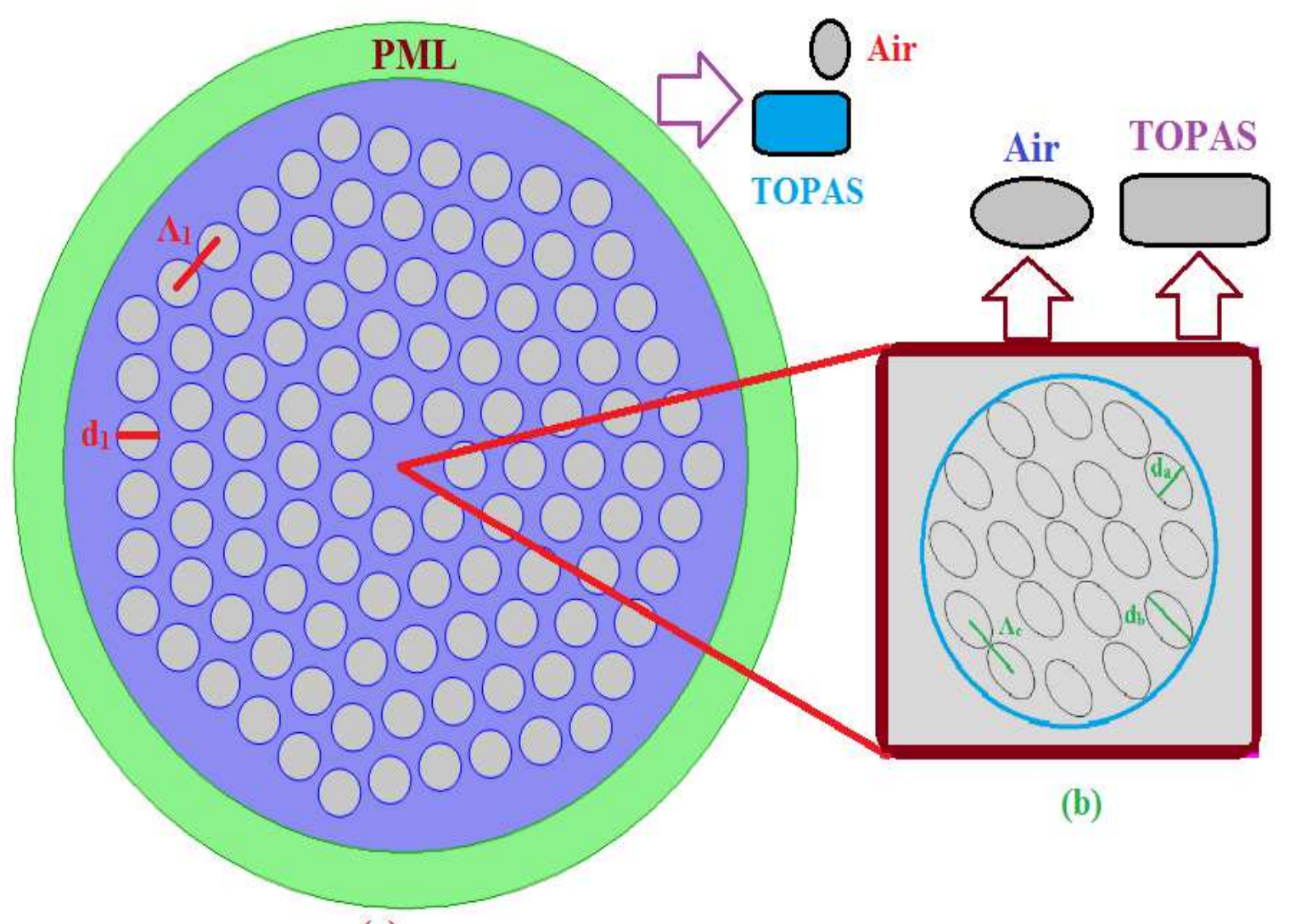

(a) 
In Fig. 1(c), we visualize that the full lights pass through the core areas strongly for modes of $\mathrm{x}$, $y$ polarization. Consequently, we get the low EML for both polarizations of modes at the operating region of $1 \mathrm{THz}$.

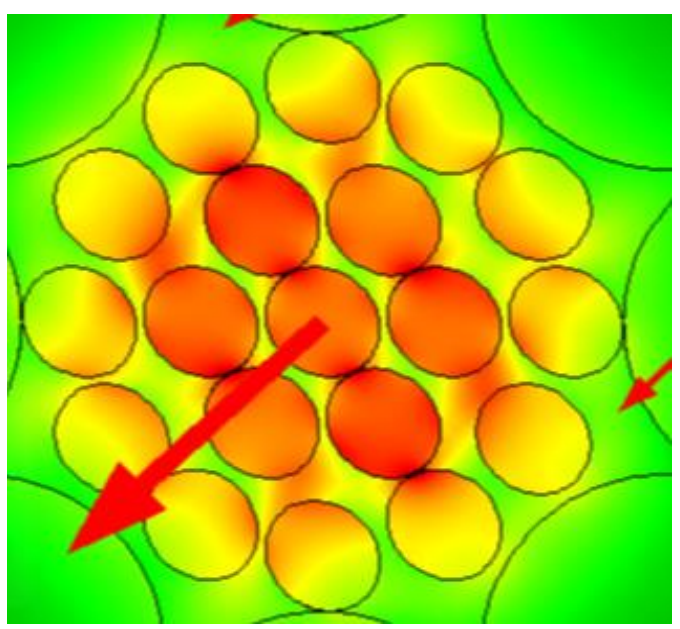

X polarization

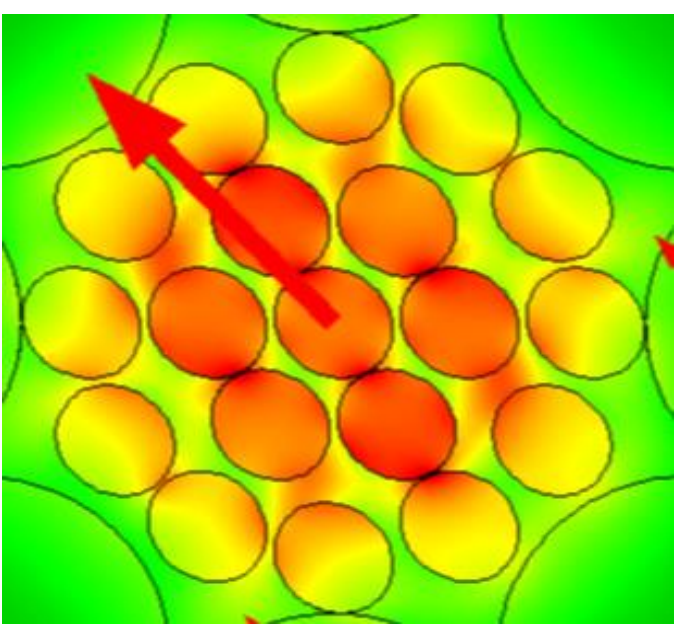

Y polarization

Fig. 1: Pictorial views of PCF along with (a) Heptagonal Cladding region (b) Rotated-hexa Elliptical Core region and (c) Mode field disseminations for polarization of $\mathrm{x}$ and the polarization of $\mathrm{y}$ at the controlling region of $1 \mathrm{THz}$.

\section{Numerical Analysis:}

TOPAS is a fabric which has been utilized in this PCF fiber to diminish the EML. Here, EML $\alpha_{\text {eff }}$ is premeditated through [31]:

$$
\alpha_{\text {effective }}=\sqrt{\frac{\varepsilon_{0}}{\mu_{0}}}\left(\frac{\int_{\text {mat }} n_{\text {mat }|E|^{2} \alpha_{\text {mat }} d A}}{\left|\int_{\text {all }} s_{Z} d A\right|}\right)\left(\mathrm{cm}^{-1}\right)
$$

Where, $\alpha_{\text {mat }}$ is the bulk material absorption loss and $n_{\text {mat }}$ is the RI of the material. $\varepsilon_{0}$ is the relative permittivity and the permeability of free space is $\mu_{0} \cdot S_{z}=\frac{1}{2}\left(E \times H^{*}\right) . z$ is the pointing vector, where, $\mathrm{z}$ is component of $\mathrm{S}_{\mathrm{z}}, \mathrm{E}$ and $\mathrm{H}^{*}$ are electric field apparatuses and the complex couple of the magnetic field.

SL of this PCF fiber is thought-out by the subsequent equation [32]:

$$
\alpha_{R}=C_{R} \times\left(\frac{f}{c}\right)^{4}(d B / k m)
$$


Where, $C_{R}$ is called the scattering coefficient.

The low confinement loss-based PCF fiber is highly used for different types of communication sectors. Here, the confinement loss $\mathrm{L}_{\mathrm{c}}$ is calculted the equation [33]:

$$
\mathrm{L}_{\mathrm{c}}=8.686 \times \mathrm{K}_{0} \operatorname{Im}\left[\mathrm{n}_{\mathrm{eff}}\right](\mathrm{dB} / \mathrm{m})
$$

Where, $K_{0}=\left(\frac{f}{c}\right)$ is the free wave number, $f$ is the frequency and $c$ are the speed of photon. $\operatorname{Im}\left[\mathrm{n}_{\mathrm{eff}}\right]$ is the imaginary part of ERI.

In this PCF fiber, the principal part is formed by the effective mode area (EMA). Here, the EMA is figured by [34]:

$$
\mathrm{A}_{\text {effective }}=\frac{\left[\int I(r t) r t d r t\right]^{2}}{\left[\int I^{2}(r t) d r t\right]^{2}}
$$

Where, Aeffective is the EMA and $\mathrm{I}(\mathrm{rr})=\left|\mathrm{E}_{\mathrm{rt}}\right|^{2}$ is the cross-sectional electric field intensity.

Power fraction $(\mathrm{PF})$ is resulted by the total power through this PCF fiber. So, the PF $\eta$ is intended by [34]:

$$
\eta=\frac{\int_{\mathrm{i}} S_{Z} d A}{\int_{\text {all }} S_{Z} d A}
$$

$\mathrm{V}$-parameter describes the mode propagation of this PCF structure. So, V-parameter is restrained by the following equation [35]:

$$
\mathrm{V}=\frac{2 \pi r f}{c} \sqrt{\mathrm{n}^{2}{ }_{\text {co }}-\mathrm{n}^{2}{ }_{\mathrm{cl}}} \leq 2.045
$$

Where, the core radius is $\mathrm{r}, \mathrm{n}_{\mathrm{co}}$ and $\mathrm{n}_{\mathrm{cl}}$ are signed by the EMI of the core and cladding area.

\section{Result Analysis and Discussions:}

COMSOL Multiphysics program is the most test system to compute completely optical properties and graphical comes about from Fig. 2 to Fig. 9 of the prescribed PCF are planned from 0.8 to $3 \mathrm{THz}$ recurrence extend. The EA of the planned PCF is outlined in Fig. 2 concurring to the recurrence changing from $1 \mathrm{THz}$ to $3 \mathrm{THz}$ for $74 \%, 70 \%$, and $66 \%$ porosities. The viable mode range is practical to be diminished slowly that appeared in Fig. 2. The EA is measured as 
$5.95 \times 10^{-8} \mathrm{~m}^{2}, 6.17 \times 10^{-8} \mathrm{~m}^{2}$ and $6.10 \times 10^{-8} \mathrm{~m}^{2}$ for $74 \%, 70 \%$ and $66 \%$ porosities individually.

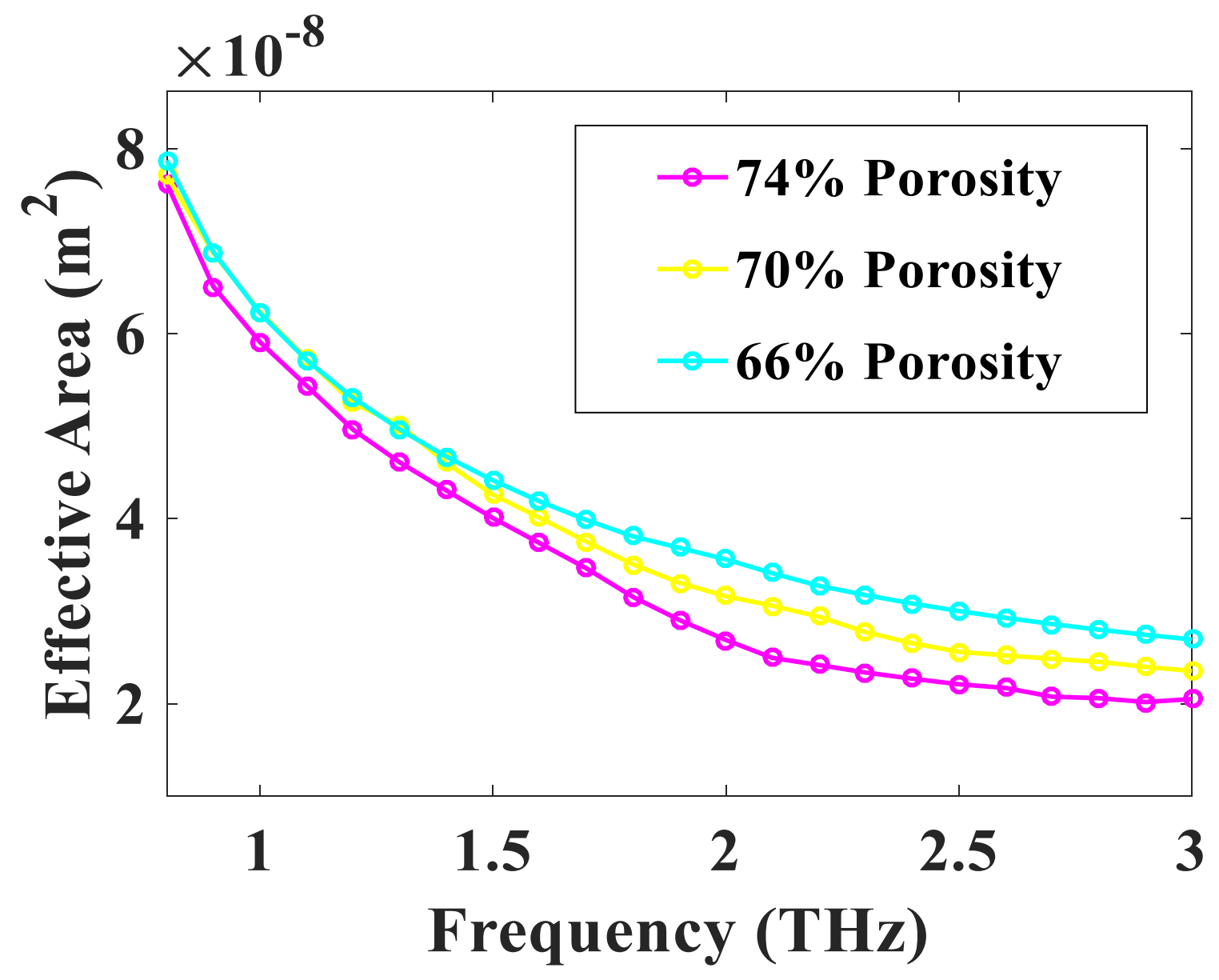

Fig. 2: EA according to the diverse frequencies such as $66 \%, 70 \%$ and $74 \%$ porosities.

Fig. 3 elucidates the EA in agreement with core diameter $\left(D_{\text {core }}\right)$ for $74 \%, 70 \%$ and $66 \%$ porosities at $1 \mathrm{THz}$. For optimum core diameter $\mathrm{D}_{\text {core }}=400 \mu \mathrm{m}$, EA is figured as $8.12 \times 10^{-8} \mathrm{~m}^{2}$, as $8.34 \times 10^{-8} \mathrm{~m}^{2}$ and as $8.64 \times 10^{-8} \mathrm{~m}^{2}$ for $74 \%, 70 \%$ and $66 \%$ porosities congruently for $1 \mathrm{THz}$ working frequency. 


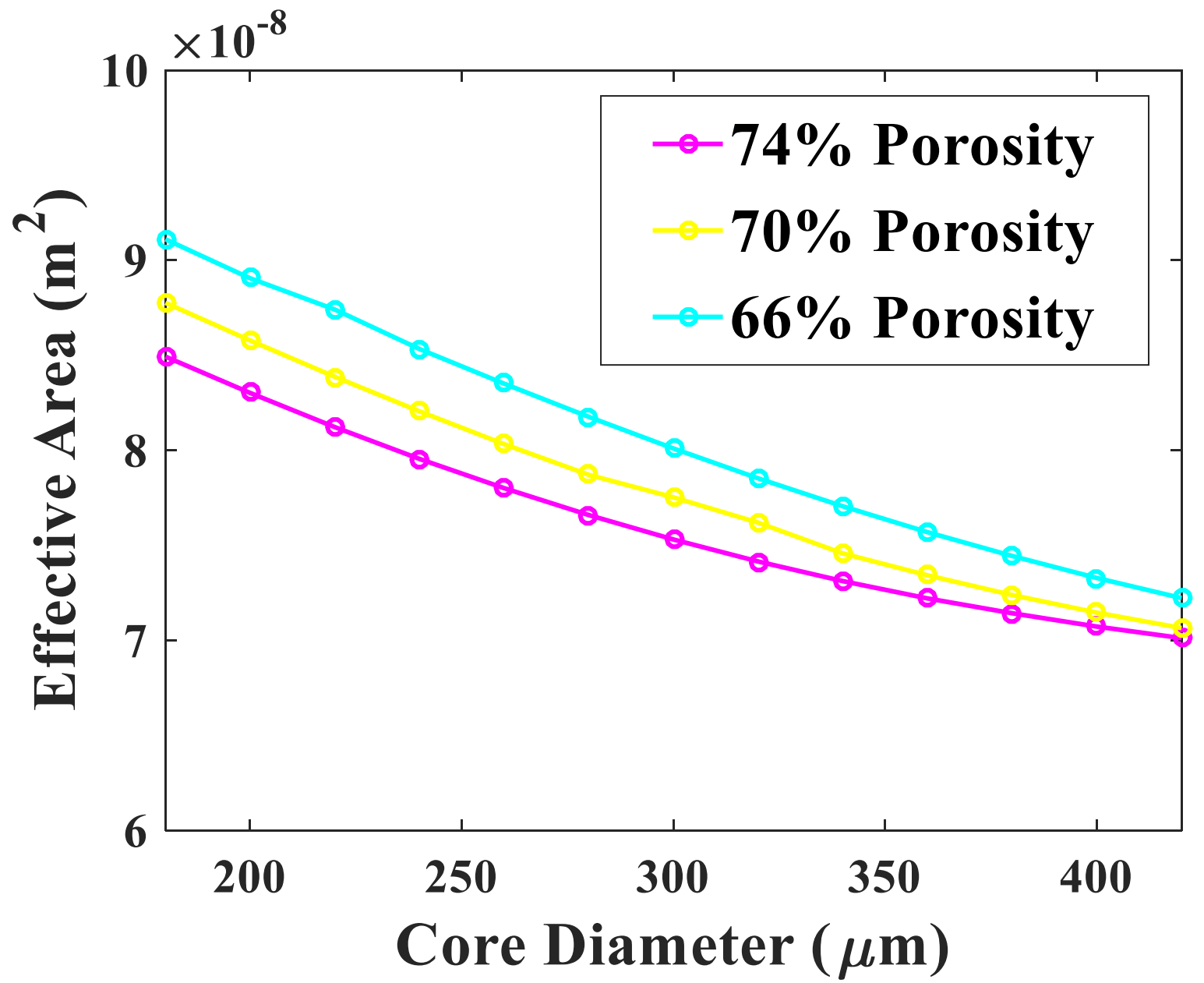

Fig. 3: EA according to the diverse core diameters such as $66 \%, 70 \%$ and $74 \%$ porosities.

Fig. 4 demonstrates the recurrence based compelling fabric misfortune (EML) chart for a few porosities. The figure indicates that the EML of proposed structure diminishes with the 
expanding of recurrence over $0.08 \mathrm{THz}$ to $3 \mathrm{THz}$ in electromagnetic range combination.

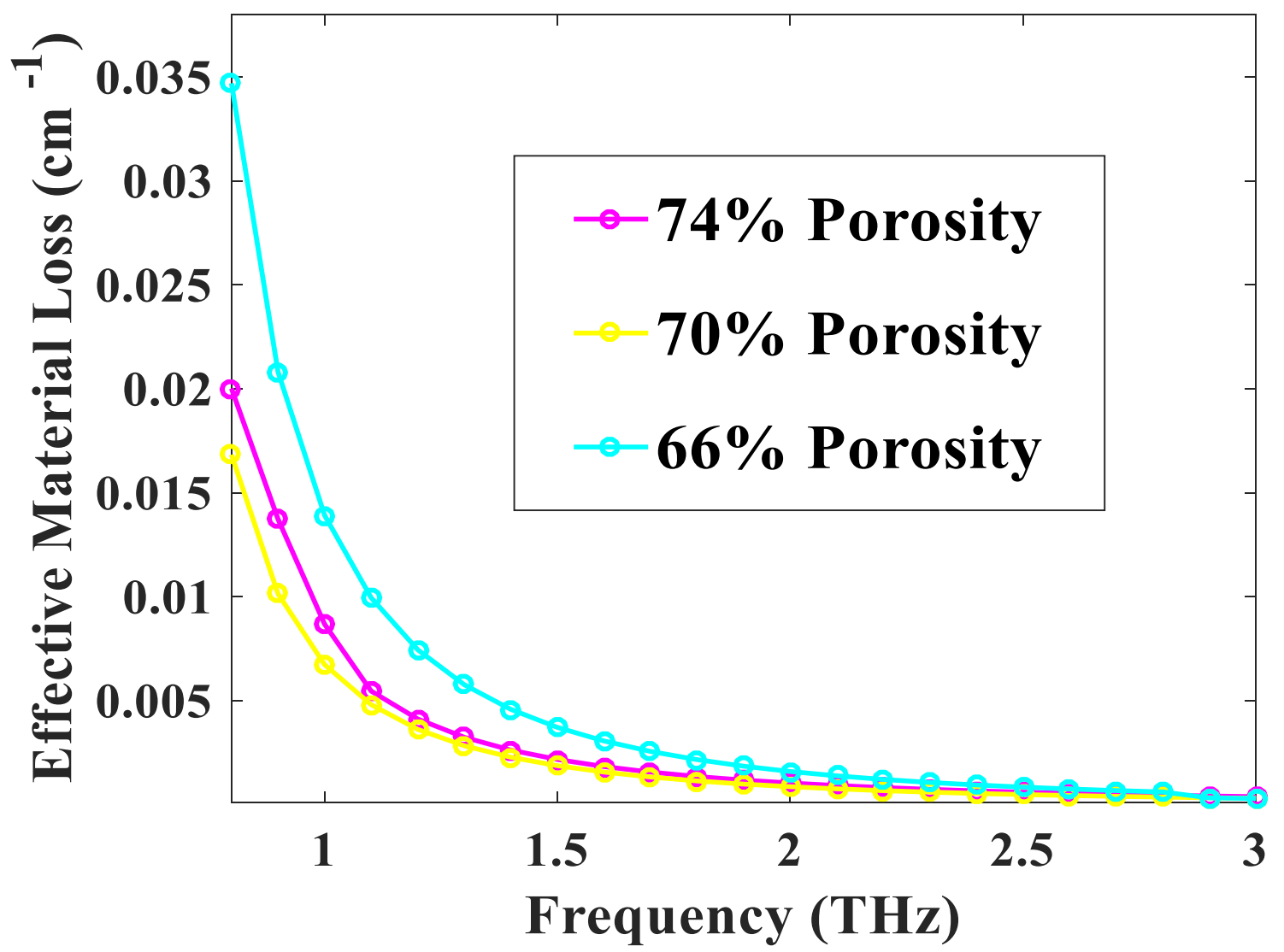

Fig. 4: EML according to the frequency such as $66 \%, 70 \%$ and $74 \%$ porosities.

In this manner, expanding of center porosity of PCF, the produced electromagnetic wave interatomic with restricted sums of fabric; the EML of the proposed strands at that point diminishes. For ideal methodology circumstances at $1 \mathrm{THz}$ recurrence, the EMLs are 0.0076 $\mathrm{cm}^{-1}, 0.0069 \mathrm{~cm}^{-1}$, and $0.0136 \mathrm{~cm}^{-1}$ for $74 \%, 70 \%$ and $66 \%$ porosities correspondingly.

EML owing to the varieties in center distance across $\left(\mathrm{D}_{\text {core }}\right)$ of proposed show with $66 \%, 70 \%$ and $74 \%$ porosities have been appeared in Fig. 5 at $1 \mathrm{THz}$ recurrence. The increments of center distance across the EML are diminishing steadily at ideal plan parameter. In our proposed PCFs $\mathrm{D}_{\text {core }}=400 \mu \mathrm{m}$ the EML is approximately $0.0076 \mathrm{~cm}^{-1}$ for $74 \%$ center porosity which is ideal esteem and not generation any complexity in manufacture. At a steady esteem of $\mathrm{D}_{\text {core, }}$ the proposed demonstrate appears the distinctive values of EML for diverse porosities. 


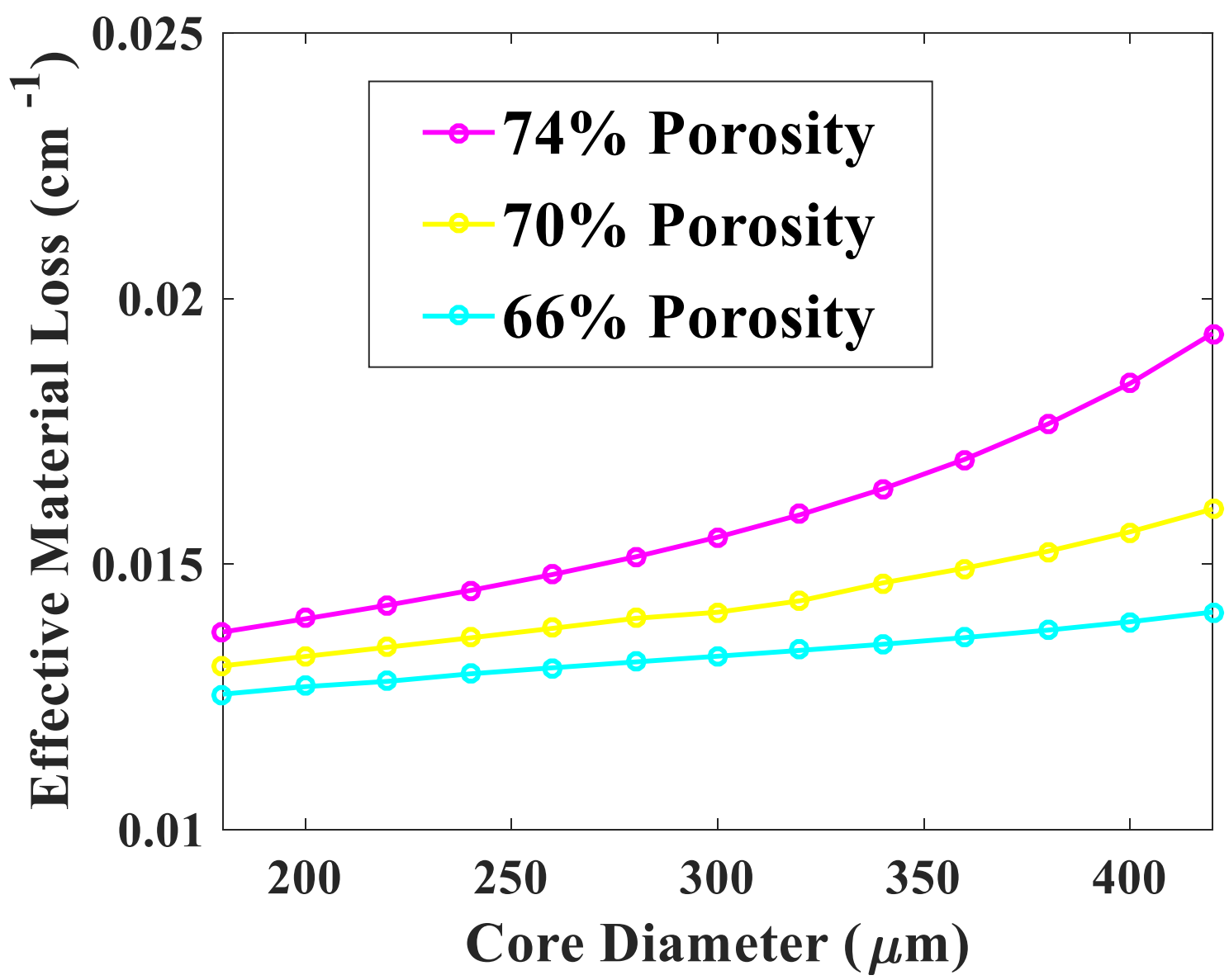

Fig. 5: EML according to the core diameters such as $66 \%, 70 \%$ and $74 \%$ porosities.

Fig. 6 shows the dispersion of control over the center, cladding and materials in agreement with recurrence at a settled $\mathrm{D}_{\text {core }}=400 \mu \mathrm{m}$. The test recurrence assortments inside $0.08 \mathrm{THz}$ to $3 \mathrm{THz}$ in electromagnetic range. Because it was found that, $90 \%$ optical control produced through the fiber center at frequency $1 \mathrm{THz}$ which suggests most extreme light contact with analytes within the center locale. Besides, the AHs in cladding locale actuated light waves to pass inside the center and give most extreme center control division. The practical control division is altogether higher than the already expressed article. 


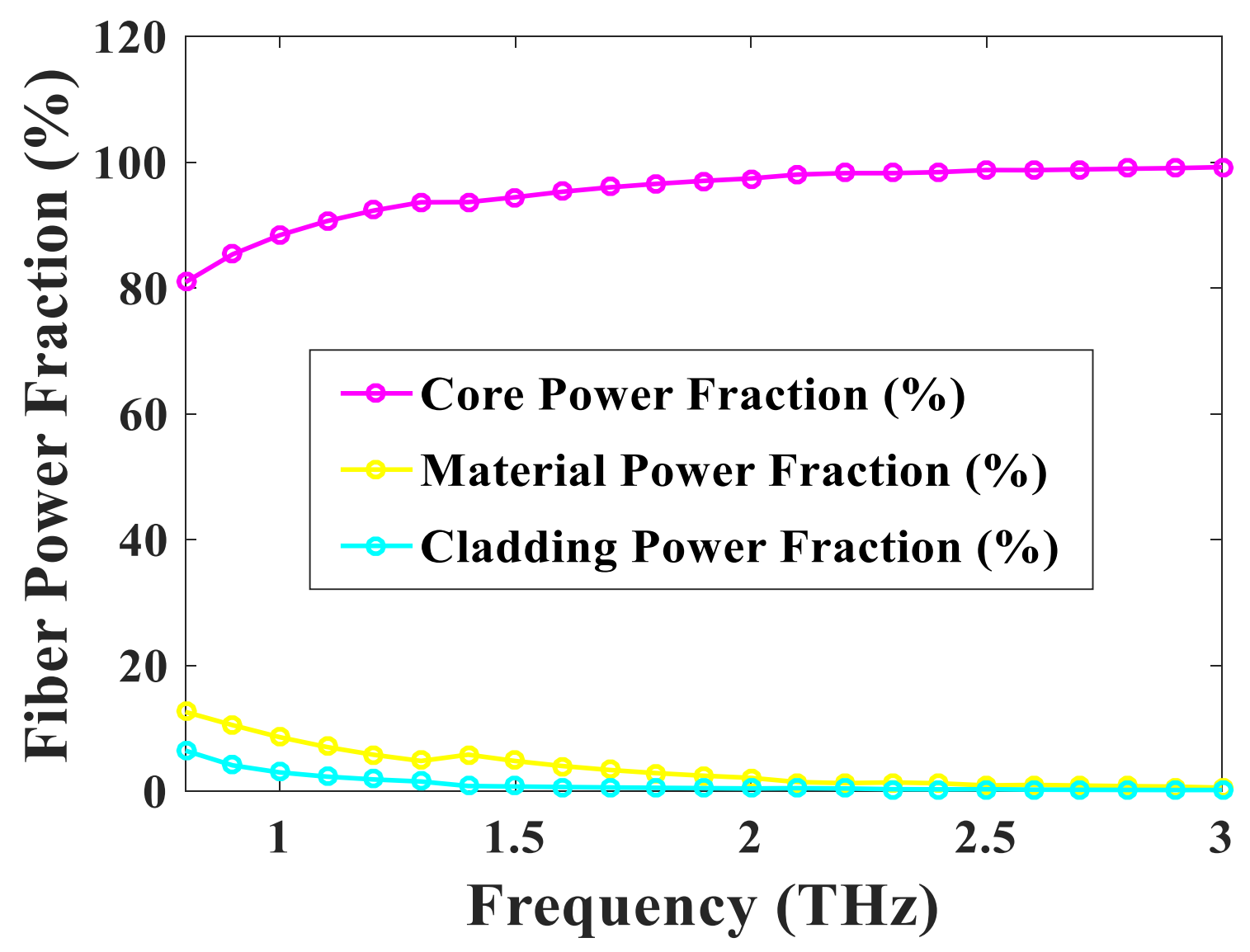

Fig. 6: Power fraction according to the different frequencies for optimum constraints.

Fig. 7 demonstrates the scattering loss examination for the varieties in wavelength in proposed structure. Scattering loss is an imperative parameter since it contributes the full misfortunes of the fiber. Scattering loss is expanding with the increments of recurrence inside 0.08 to $3 \mathrm{THz}$ extend showed up in Fig. 7 where's the $D_{\text {core }}=400 \mu \mathrm{m}$. The picked-up diffusing misfortune of proposed PCF is $1.24 \times 10^{-10} \mathrm{~dB} / \mathrm{km}$ at optical wavelength $1 \mathrm{THz}$ which is irrelevant. 


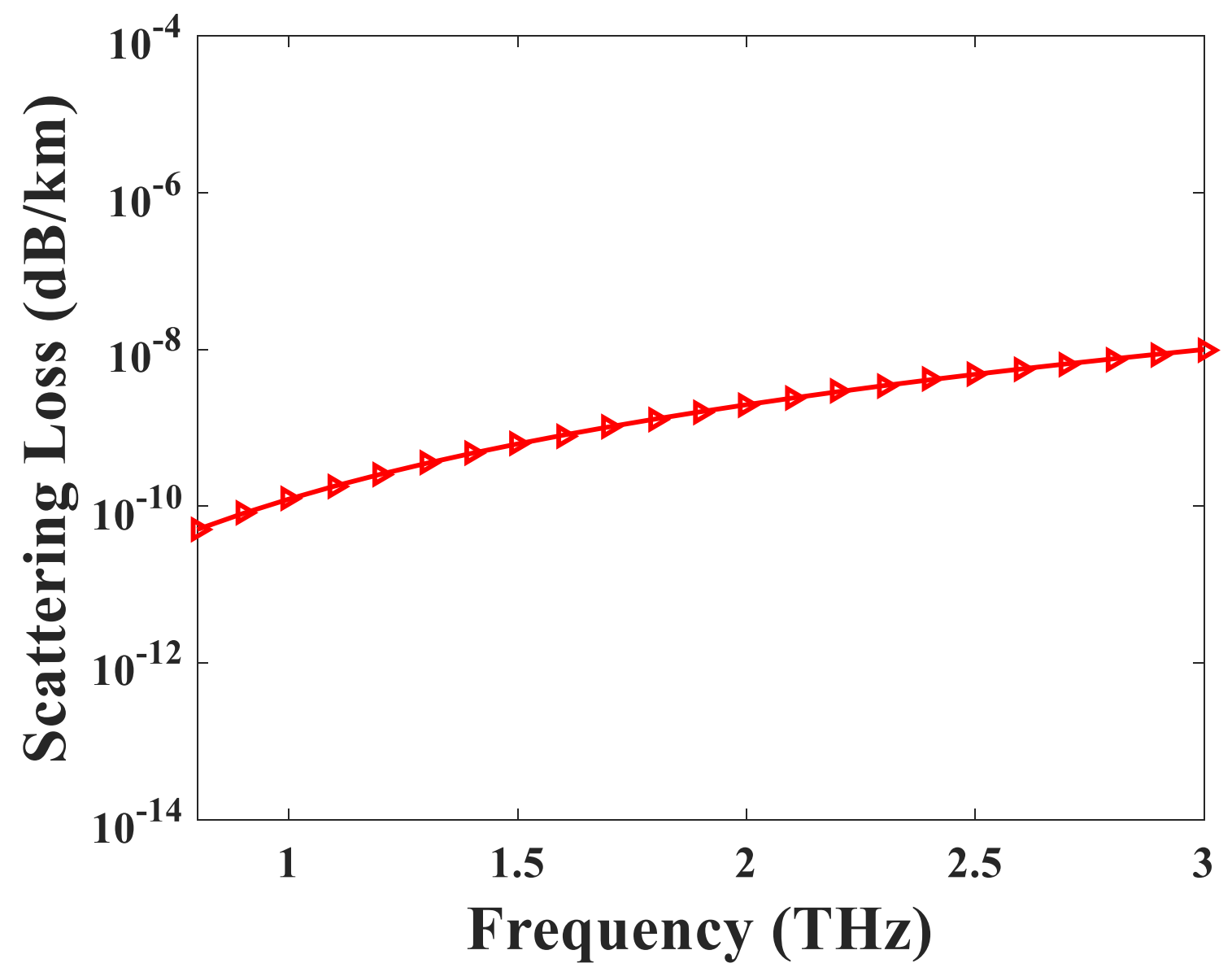

Fig. 7: Scattering loss according to the different frequencies for optimum design parameters.

Fig. 8 outlines the conduct of CL concurring to recurrence at ideal plan parameter. Confinement loss (CL) of proposed demonstrate is being diminished due to rising of recurrence over 0.08 to 3 THz. When light passes through the center with tall recurrence at that point it moves forward the file differentiate of center and cladding and hence minimize the restriction misfortune. The CL of expected development at ideal plan limitations for $1 \mathrm{THz}$ of $3.35 \times 10^{-16} \mathrm{~dB} / \mathrm{m}$. 


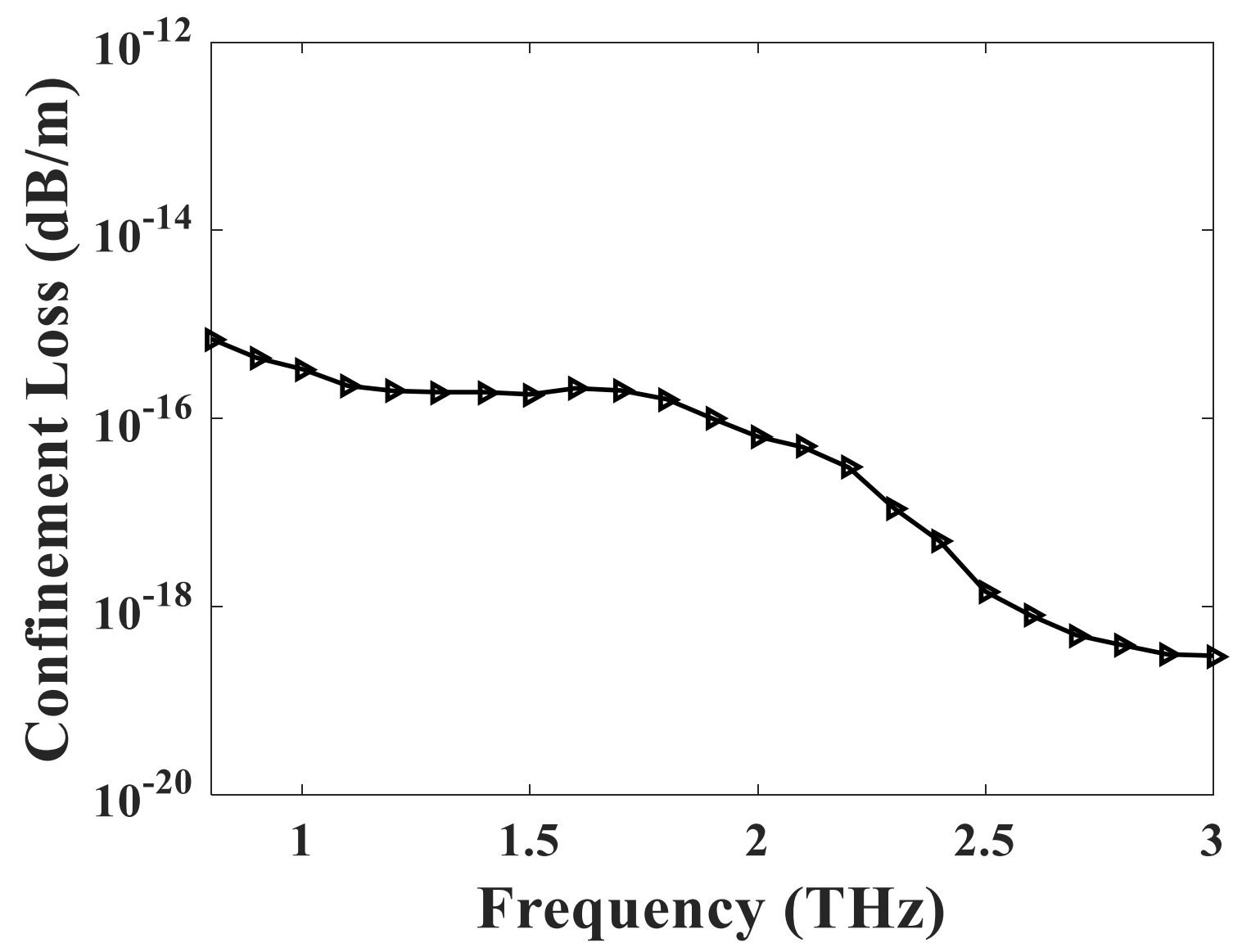

Fig. 8: Confinement loss according to the different frequencies for optimum design parameters. $V_{\text {eff }}$ is explored as the function of frequency for optimal enterprise constraint at $D_{\text {core }}=400 \mathrm{um}$ which has been revealed in Fig. 9. Here, the optimum constraints are cladding distance across $d_{1}$ $=\mathrm{d}_{2}=\mathrm{d}_{3}=\mathrm{d}_{4}=\mathrm{d}_{5}=299 \mu \mathrm{m}$, cladding pitch $\mathrm{A}_{1}=\mathrm{A}_{2}=\mathrm{A}_{3}=\mathrm{A}_{4}=\mathrm{A}_{5}=355 \mu \mathrm{m}$, center distance across $d_{a}=54 \mu \mathrm{m}, d_{b}=56 \mu \mathrm{m}$ and center pitch $A_{c}=60 \mu \mathrm{m}$. 


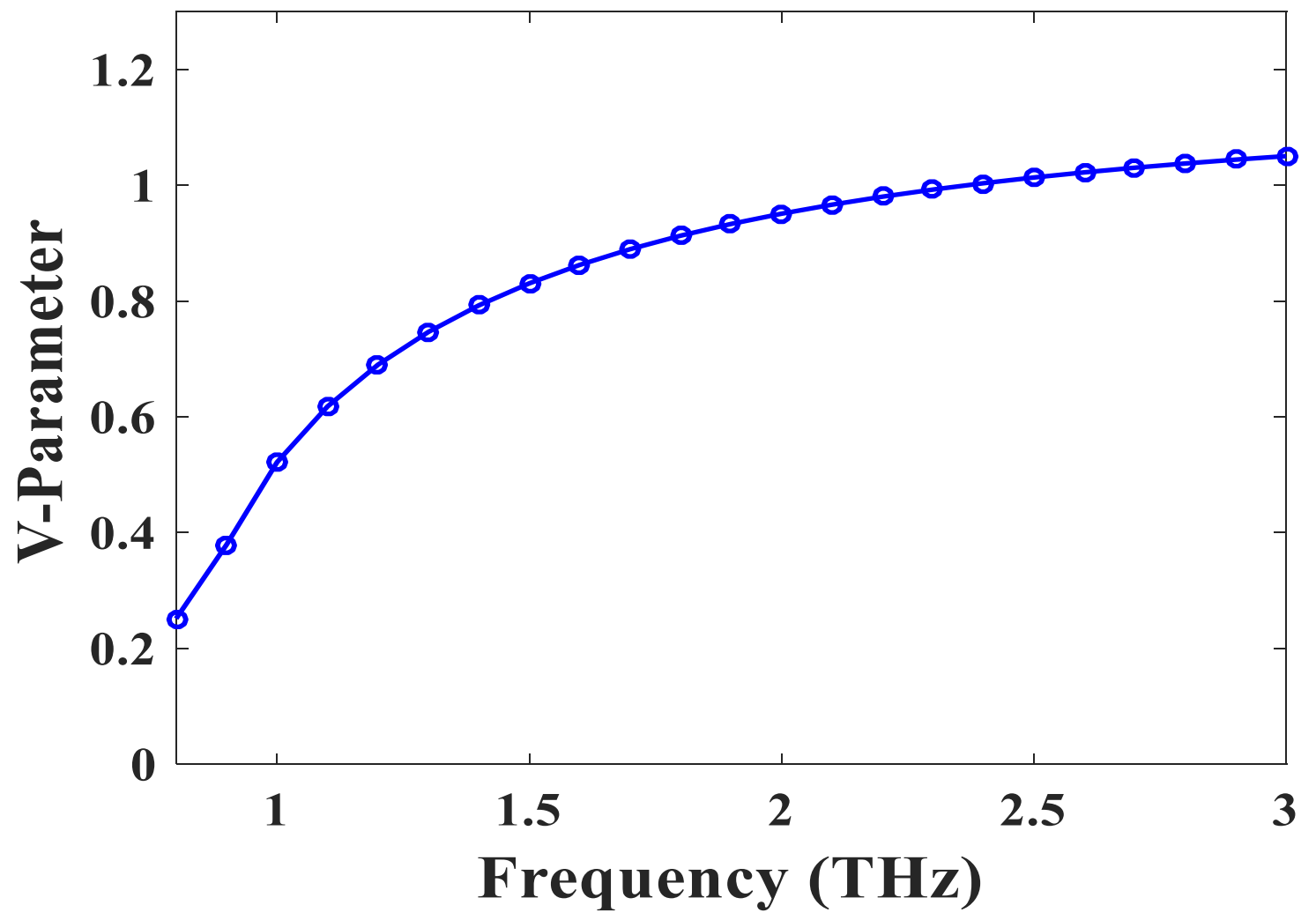

Fig. 9: V-parameter according to the different frequencies for optimum design parameters.

The designed PCF shows EML, confinement loss, core power fraction, and effective area belongings than other designed PCFs at $1 \mathrm{THz}$ functional frequency as providing in Table 1 .

Table 1: Propagation comparison among Prior PCFs and of the proposed H-PCF.

$\begin{array}{cccccc}\text { Ref. } & \begin{array}{c}\text { EML } \\ \left(\mathrm{cm}^{-1}\right)\end{array} & \begin{array}{c}\text { Porosity } \\ (\%)\end{array} & \begin{array}{c}\text { Power Fraction } \\ (\%)\end{array} & \begin{array}{c}\text { Confinement } \\ \text { Loss }(\mathrm{dB} / \mathrm{m})\end{array} & \begin{array}{c}\text { Effective } \\ \text { Area }\left(\mathrm{A}_{\text {eff }}\right. \\ \left.\left(\mathrm{m}^{2}\right)\right)\end{array} \\ {[36]} & 0.100 & 30 & - & 1.0 \times 10^{-01} & 2.3 \times 10^{-07} \\ {[37]} & 0.089 & 60 & 37 \% & 1.0 \times 10^{-02} & 9.77 \times 10^{-08} \\ {[38]} & 0.076 & 80 & 53 \% & 8.96 \times 10^{-01} & - \\ {[39]} & 0.038 & 74 & 56 \% & 2.35 \times 10^{-01} & 6.75 \times 10^{-05} \\ {[40]} & 0.110 & - & - & - & 0.98 \times 10^{-07} \\ {[41]} & 0.027 & 85 & 83 \% & 1.0 \times 10^{-02} & 9.48 \times 10^{-08} \\ {[42]} & 0.068 & 50 & - & - & - \\ {[43]} & 0.050 & 60 & 42 \% & 1.00 & - \\ {[44]} & 0.07 & 30 & - & 1.14 \times 10^{-3} & 1.07 \times 10^{-9} \\ {[45]} & 0.05 & - & 67 \% & 7.79 \times 10^{-12} & 2.00 \times 10^{-5}\end{array}$




\begin{tabular}{|c|c|c|c|c|c|}
\hline [46] & 0.078 & 30 & - & $1.39 \times 10^{-4}$ & - \\
\hline [47] & 0.043 & 81 & $47 \%$ & $1.00 \times 10^{-2}$ & $2.15 \times 10^{-5}$ \\
\hline $\begin{array}{c}\text { Proposed } \\
\text { H-PCF }\end{array}$ & 0.0076 & 74 & $90 \%$ & $3.35 \times 10^{-16}$ & $5.95 \times 10^{-8}$ \\
\hline
\end{tabular}

It has been found Table 1 which shows better outputs compare to the former research work. We have found EML $0.0076 \mathrm{~cm}^{-1}$, power fraction $90 \%$, Confinement loss $3.35 \times 10^{-16} \mathrm{~dB} / \mathrm{m}$ and effective area is $5.95 \times 10^{-8} \mathrm{~m}^{2}$ at monitoring region of $1 \mathrm{THz}$.

\section{Conclusion:}

A fabulous plan of heptagonal cladding range with curved turned rotated-hexa based center locale are advertised for communication areas with reducing diverse sorts of misfortunes such as EML, imprisonment misfortune, and scrambling misfortune. TOPAS is the foundations significant to expel diverse misfortunes compare to the previous investigate work. Here, moo EML of $0.0076 \mathrm{~cm}^{-1}$ has been achieved at $1 \mathrm{THz}$ possessed run. By utilizing the heptagonal PCF concept, all reenactment comes about have been accomplished with the FEM and PML boundary conditions based on COMSOL Multiphysics test system. This designed PCF fiber uncovers low EML of $0.0076 \mathrm{~cm}^{-1}$, with expansive a viable region (EA) of $5.95 \times 10^{-8} \mathrm{~m}^{2}$ and stream of control within the center locale of $90 \%$ at $1 \mathrm{THz}$. In addition, the proposed He-PCF moreover has other useful profiles like as standard control due to EML $\left(<0.0076 \mathrm{~cm}^{-1}\right)$, low confinement loss $(\sim 3.35$ $\left.\mathrm{x} 10^{-16} \mathrm{~cm}^{-1}\right)$, and high-power division of the center ( 90\%). Thus, this anticipated PCF would be a favorable candidate within the field telecommunication, IoT based wireless sensor network, others communication which is now under investigation.

Conflict of Interest: The authors declare that they have no conflict of interest.

Acknowledgement: The authors are grateful to the participants who contributed to this research. The authors have not received any funding for this research.

\section{References:}

[1] Abbott, D., Zhang, X.C.: Scanning the issue: T-ray imaging, sensing, and retection. Proc. IEEE 95(8), 1509-1513 (2007).

[2] Islam, M.I., Ahmed, K., Sen, S., Chowdhury, S., Paul, B.K., Islam, M.S., Asaduzzaman, S.: Design and optimization of photonic crystal fiber-based sensor for gas condensate and air pollution monitoring. Photonic Sens 7(3), 234-245 (2017).

[3] Tonouchi, M.: Cutting-edge terahertz technology. Nat. Photon 1, 97-105 (2007). 
[4] Pinto, D., Obayya, S.S.A.: Improved complex envelope alternative direction implicit finite difference time domain method for photonic bandgap cavities. IEEE J. Lightwave Technol. 25(1), 440-447 (2007).

[5] M. Nagel, P. H. Bolivar, M. Brucherseifer, H. Kurz, A. Bosserhoff, and R. Büttner, "Integrated THz technology for label-free geneticdiagnostics," Appl. Phys. Lett., vol. 80, no. 1, pp. 154-156, 2002.

[6] J. Zhang and D. Grischkowsky, "Waveguide terahertz time-domain spectroscopy of nanometer water layers," Opt. Lett., vol. 29, no. 14, pp. 1617-1619, 2004. [].Vigneswaran, D., Ayyanar, N., Sharma, M., Sumathi, M., Rajan, M., Porsezian, K.: Salinity sensor using photonic crystal fber. Sens. Actuators A Phys. 269, 22-28 (2018)

[7] Amiri, I.S.; Paul, B.K.; Ahmed, K.; Aly, A.H.; Zakaria, R.; Yupapin, P.; Vigneswaran, D. Tri-core photonic crystal fiber based refractive index dual sensor for salinity and temperature detection. Microw. Opt. Technol. Lett. 2018.

[8] Kodo Kawase, Yuichi Ogawa, Yuuki Watanabe, and Hiroyuki Inoue, "Nondestructive terahertz imaging of illicit drugs using spectral fingerprints," Optics Express Vol. 11, Issue 20, pp. 2549-2554 (2003).

[9] Rogalski, A., 2018. Terahertz Detectors. Encyclopedia of Modern Optics, p.418. [9]. S. Islam, S. Rana, M. R. Islam, M. Faisal, H. Rahman, and J. Sultana,"Porous core photonic crystal fiber for ultra-low material loss in THz regime," IET Commun., vol. 10, no. 16, pp. 2179-2183, 2016.

[10] Wang, K., Mittleman, D.M.: Metal wires for terahertz waveguiding. Nature 432, 376-379 (2004).

[11] Bowden, B., Harrington, J.A., Mitrofanov, O.: Silver/polystyrenecoated hollow glass waveguides for the transmission of terahertz radiation. Opt. Lett. 32(20), 2945-2947(2007)

[12] Skorobogatiy, M., Dupuis, A.: Ferroelectric all-polymer hollow Bragg fibers for terahertz guidance. Appl. Phys. Lett. 90(11),113514 (2007).

[13] Jeon, T. I., Zhang, J., and Grischkowsky, D., 'THz Somerfeld wave propagation on a single metal wire', Applied Phys. Lett., 2005, 86, (16), pp 161904.

[14] Chen, L., Chen, H., Kao, T., Lu, J., Sun, C.: Low-loss subwavelength plastic fiber for terahertz wave guiding. Opt. Lett. 31(3), 308-310 (2006)

[15] Hassani, A., Dupuis, A., Skorobogatiy, M.: Porous polymer fibers for low-loss terahertz guiding. Opt. Express 16(9), 6340-6351(2008)

[16] X. Tang, Y. Jiang, B. Sun, J. Chen, X. Zhu, P. Zhou, D. Wu, and Y. Shi, IEEE Photonics Technology Letters 25, 331 (2013).

[17] W. Yuan, L. Khan, D. J. Webb, K. Kalli, H. K. Rasmussen, A. Stefani, O. Bang, "Humidity insensitive TOPAS polymer ber Bragg grating sensor", Opt. Express, vol. 19, no. 20, pp. 19731-19739(2011).

[18] M. Goto, A. Quema, H. Takahashi, S. Ono, and N. Sarukura, Japanese Journal of Applied Physics 43, 317 (2004).

[19] G. Pastorelli, T. Trafela, P. F. Taday, A. Portieri, D. Lowe, K. Fukunaga, and M. Strlic, Analytical and Bioanalytical Chemistry 403, 1405 (2012).

[20] X. Jiang, N. Y. Joly, M. A. Finger, F. Babic, G. K. Wong, J. C. Travers, P. S. J. Russell, "Deep-ultraviolet to mid-infrared super continuum generated in solidcore ZBLAN photonic crystal fiber", Nat. Photonics, vol.9, no. 2, pp. 133-139, 2015.

[21] Dash, J.N., Jha, R.: Graphene-based birefringent photonic crystal fber sensor using surface plasmon resonance. IEEE Photon. Technol. Lett. 26(11), 1092-1095 (2014 [22]. M. S. Islam, J. Sultana, S. Rana, M. R. Islam, M. Faisal, S. F. Kaijage, and D. Abbott, Optical Fiber Technology 34, 6 (2017).

[22] Bao, H., Nielsen, K., Rasmussen, H.K., Jepsen, P.U., Bang, O.: Fabrication and characterization of porouscore honeycomb bandgap THz fibers. Opt. Express 20(28), 29507-29517 (2012).

[23] Islam, R.; Rana, S.; Ahmad, R.; Kaijage, S.F. Bend-insensitive and low-loss porous core spiral terahertz fiber, IEEE Photon. Technol. Lett. 2015, 27, 2242-2245.

[24] Hasanuzzaman, G.K.M., Habib, S., Razzak, S.M.A.: Low loss single-mode porous-core kagome photonic crystal fiber for THz wave guidance. J. Lightwave Technol. 33(19), 4027-4031 (2015). 
[25] Hasan, M.R.; Islam, M.A.; Anower, M.S.; Razzak, S.M.A. Low-loss and bendinsensitive terahertz fiber using a rhombic-shaped core. Appl. Opt. 2016, 55, 8441- 8447.

[26] Islam, S., Islam, M.R., Faisal, M., Arefin, A.S.M.S., Rahman, H., Sultana, J., Rana, Sohel: Extremely lowloss, dispersion flattened porous-core photonic crystal fiber for terahertz regime. Opt. Eng. 55(7), 076117 (2016).

[27] M.S. Hossain, S. Sen, "Design and Performance Improvement of Optical Chemical Sensor Based Photonic Crystal Fiber (PCF) in the Terahertz (THz) Wave Propagation", Silicon (2020), https://doi.org/10.1007/s12633-020-00696-8

[28] F. A. Mou, M. M. Rahman, M. A. Al Mahmud, M. R. Islam and M. I. H. Bhuiyan, "Design and Characterization of a Low Loss Polarization Maintaining Photonic Crystal Fiber for THz Regime," 2019 IEEE International Conference on Telecommunications and Photonics (ICTP), Dhaka, Bangladesh, 2019, pp. 1-4, doi: 10.1109/ICTP48844.2019.9041715.

[29] J. Sultana, M. R. Islam, M. Faisal, K. M. A. Talha, M. S. Islam, "Design and analysis of a Zeonex based diamond-shaped core kagome lattice photonic crystal fiber for T-ray wave transmission," Optical Fiber Technology 47, 55-60, (2019).

[30] B. K. Paul, K. Ahmed, "Analysis of terahertz waveguide properties of Q-PCF based on FEM scheme," Optical Materials 100, 109634, (2020)

[31] Raonaqul Islam, G. K. M. Hasanuzzaman, Md. Anwar Sadath, Sohel Rana, Md. Selim Habib, "Extremely low-loss single-mode photonic crystal fiber in the terahertz regime", Electrical \& Electronic Engineering (ICEEE) 2015 International Conference on, pp. 289-292, 2015.

[32] R. Pennetta, M.T. Enders, M.H. Frosz, F. Tani, P.S.J. Russell, "Fabrication and non-destructive characterization of tapered single-ring hollow-core photonic crystal fiber", APL Photonics 4 (5) (2019), https://doi.org/10.1063/1.5093474, 056105.

[33] M. Nagel et al., "THz technology for label-free genetic diagnostics", The 15th Annual Meeting of the IEEE Lasers and Electro-Optics Society, Glasgow, UK, 2002, pp. 345-346 vol.1, doi: 10.1109/LEOS.2002.1134071.

[34] Paul BK, Ahmed K. "Highly birefringent TOPAS based single mode photonic crystal fiber with ultra-low material loss for Terahertz applications”, Optical Fiber Technol. (2019) 53:102031. doi: 10.1016/j.yofte.2019.102031

[35] Islam R, Rana S, Ahmad R, Kaijage SF. Bend-insensitive and low-loss porous core spiral terahertz fiber. IEEE Photon Technol Lett. 2015; 27(21):2242-2245. DOI:10.1109/LPT.2015.2457941.

[36] Hasan MR, Islam MA, Anower MS, Razzak SM. Low-loss and bend-insensitive terahertz fiber using a rhombic-shaped core. Appl Opt. 2016; 55(30):8441-8447. DOI:10.1364/AO.55.008441.

[37] Hasan MR, Islam MA, Rifat AA. A single mode porous-core square lattice photonic crystal fiber for THz wave propagation Eur Opt Soc Rapid Publ. 2016;12(1):15. DOI:10. 1186/s41476-016-0017-5.

[38] Paul BK, Ahmed K. Analysis of terahertz waveguide properties of Q-PCF based on FEM scheme. Opt Mater. 2020; 100:109634.

[39] Islam R, Habib MS, Hasanuzzaman GKM, Rana S, Sadath MA, Markos C. A novel low-loss diamond-core porous fiber for polarization maintaining terahertz transmission. IEEE Photon Technol Lett. 2016; 28(14):1537-1540.

[40] Paul BK, Bhuiyan T, Abdulrazak LF, Sarker K, Hassan MM, Shariful S, Ahmed K. extremely low loss optical waveguide for terahertz pulse guidance. Results in Physics. 2019; 15:102666.

[41] Ahmed K, Chowdhury S, Paul BK, Islam MS, Sen S, Islam MI,et al. Ultrahigh birefringence, ultralow material loss porous core single-mode fiber for terahertz wave guidance. Appl Opt. 2017;56(12):34773483. DOI:10.1364/AO.56.003477. 
[42] Rana S, Hasanuzzaman GK, Habib S, Kaijage SF, Islam R.Proposal for a low loss porous core octagonal photonic crystal fiber for T-ray wave guiding. Opt Eng. 2014;53(11):115107-115107. DOI:10.1117/1.OE.53.11.115107.

[43] Ahasan Habib, M., Shamim Anower, M., \& Rabiul Hasan, M. Highly birefringent and low effective material loss microstructure fiber for THz wave guidance. Optics Communications. 2018; 423, 140-144. doi: 10.1016/j.optcom.2018.04.022

[44] Sultana, J., Islam, M. S., Ahmed, K., Dinovitser, A., Ng, B. W.-H., \& Abbott, D. Terahertz detection of alcohol using a photonic crystal fiber sensor. Applied Optics. 2018; 57(10), 2426. doi:10.1364/ao.57.002426

[45] Sultana, J., Islam, M. S., Islam, M. R., \& Abbott, D. High numerical aperture, highly birefringent novel photonic crystal fibre for medical imaging applications. Electronics Letters. 2018; 54(2), 61-62. doi:10.1049/el.2017.3694

[46] Islam, M. S., Sultana, J., Rana, S., Islam, M. R., Faisal, M., Kaijage, S. F., \& Abbott, D. Extremely low material loss and dispersion flattened TOPAS based circular porous fiber for long distance terahertz wave transmission. Optical Fiber Technology. 2017; 34, 6-11. doi: 10.1016/j.yofte.2016.11.014 


\section{Figures}

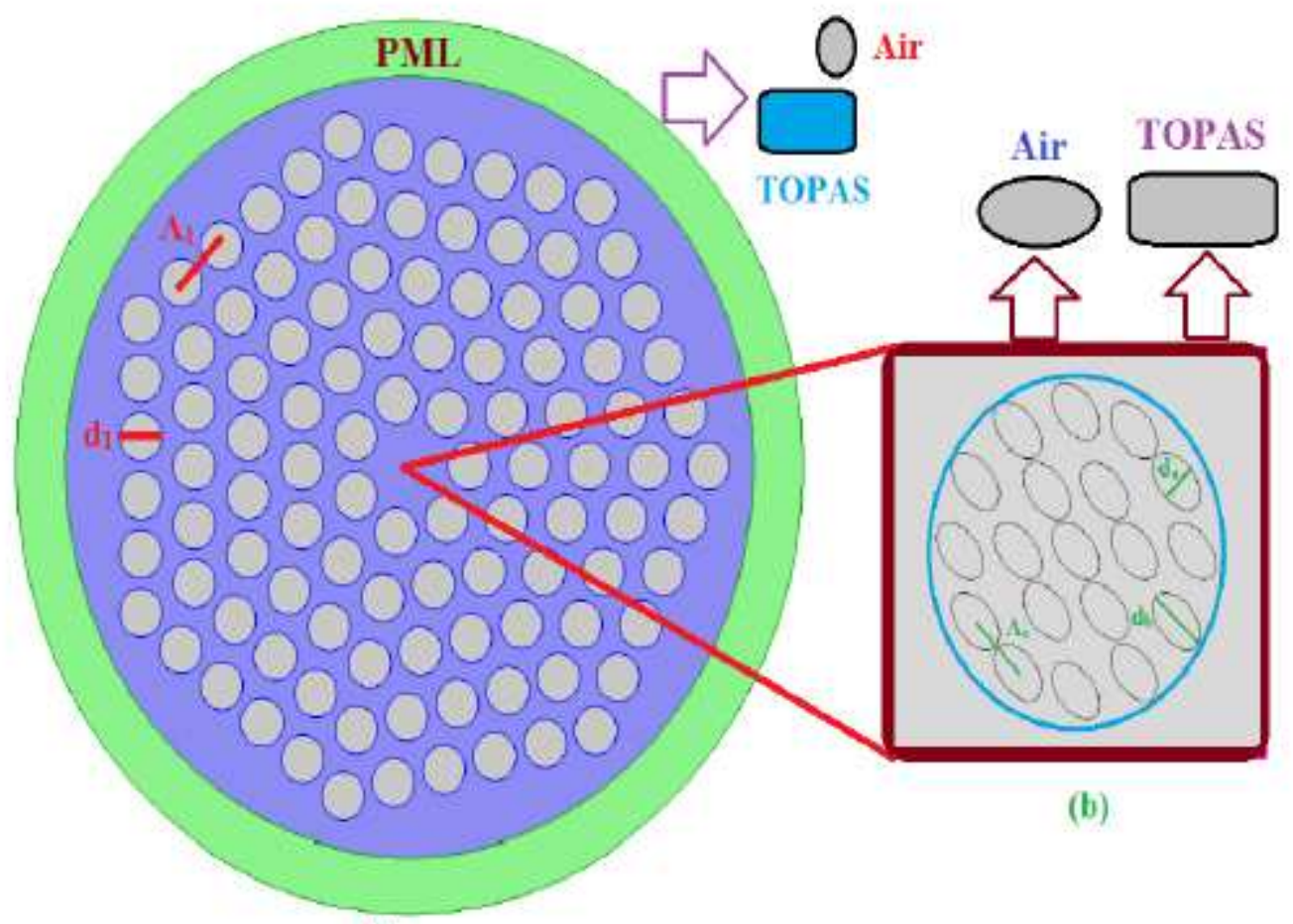

(a)

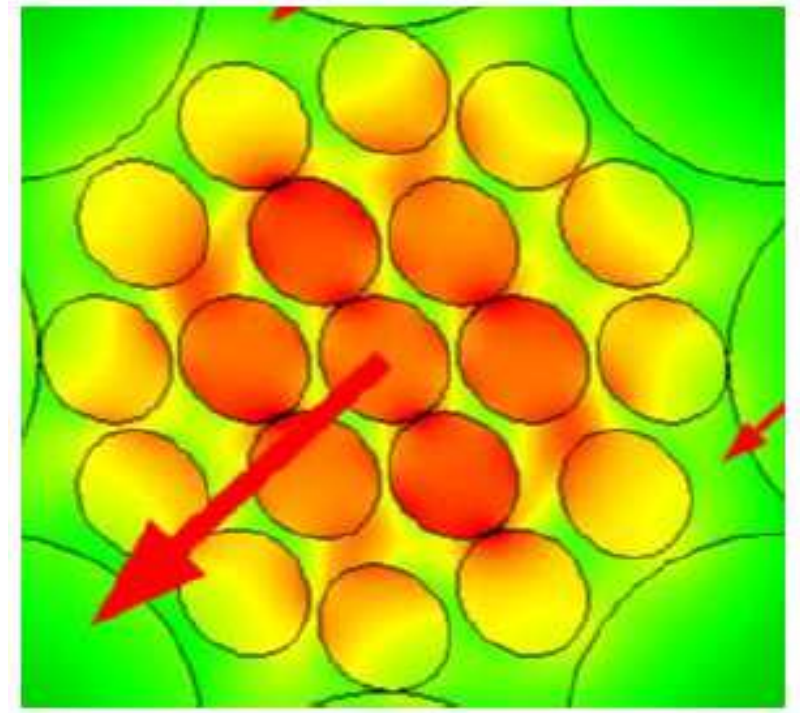

$\mathrm{X}$ polarization

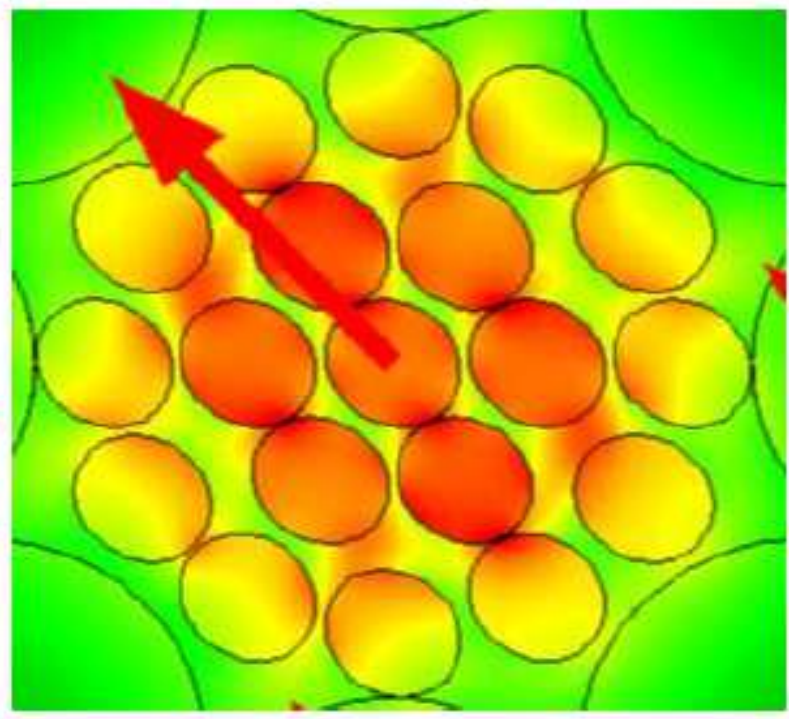

Y polarization

\section{Figure 1}

Pictorial views of PCF along with (a) Heptagonal Cladding region (b) Rotated-hexa Elliptical Core region and (c) Mode field disseminations for polarization of $x$ and the polarization of $y$ at the controlling region of $1 \mathrm{THz}$. 


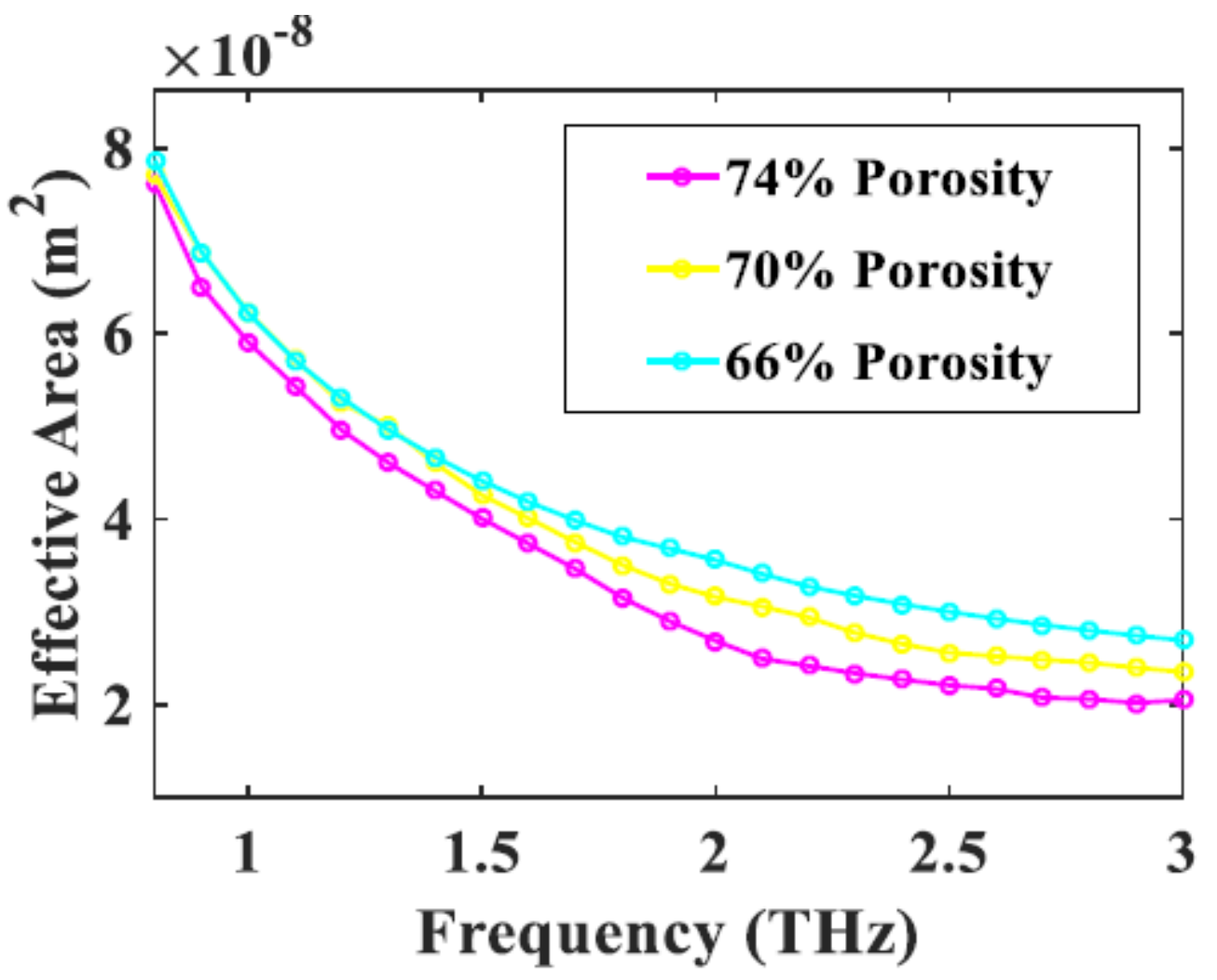

Figure 2

EA according to the diverse frequencies such as $66 \%, 70 \%$ and $74 \%$ porosities.

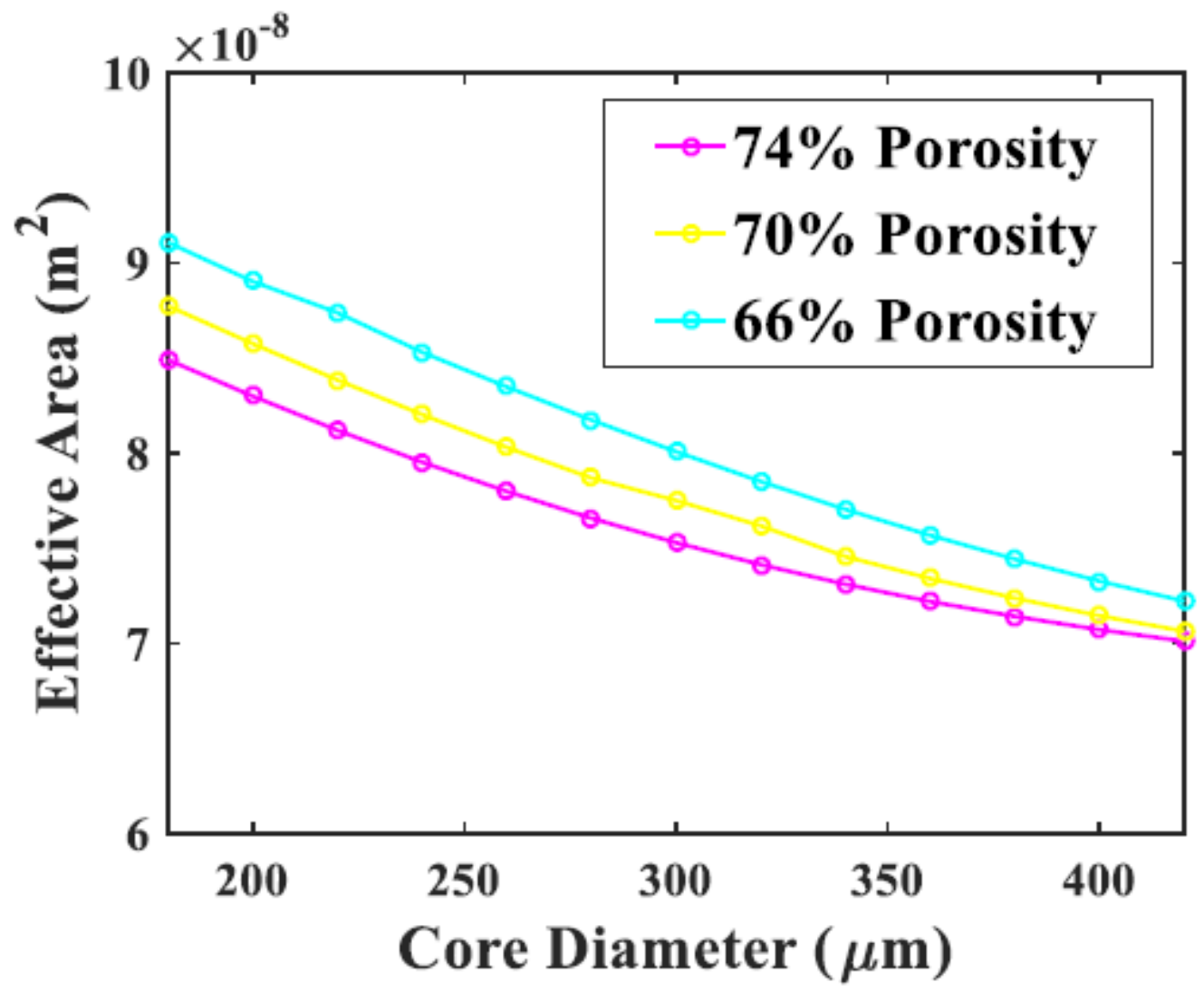

Figure 3 
EA according to the diverse core diameters such as $66 \%, 70 \%$ and $74 \%$ porosities.

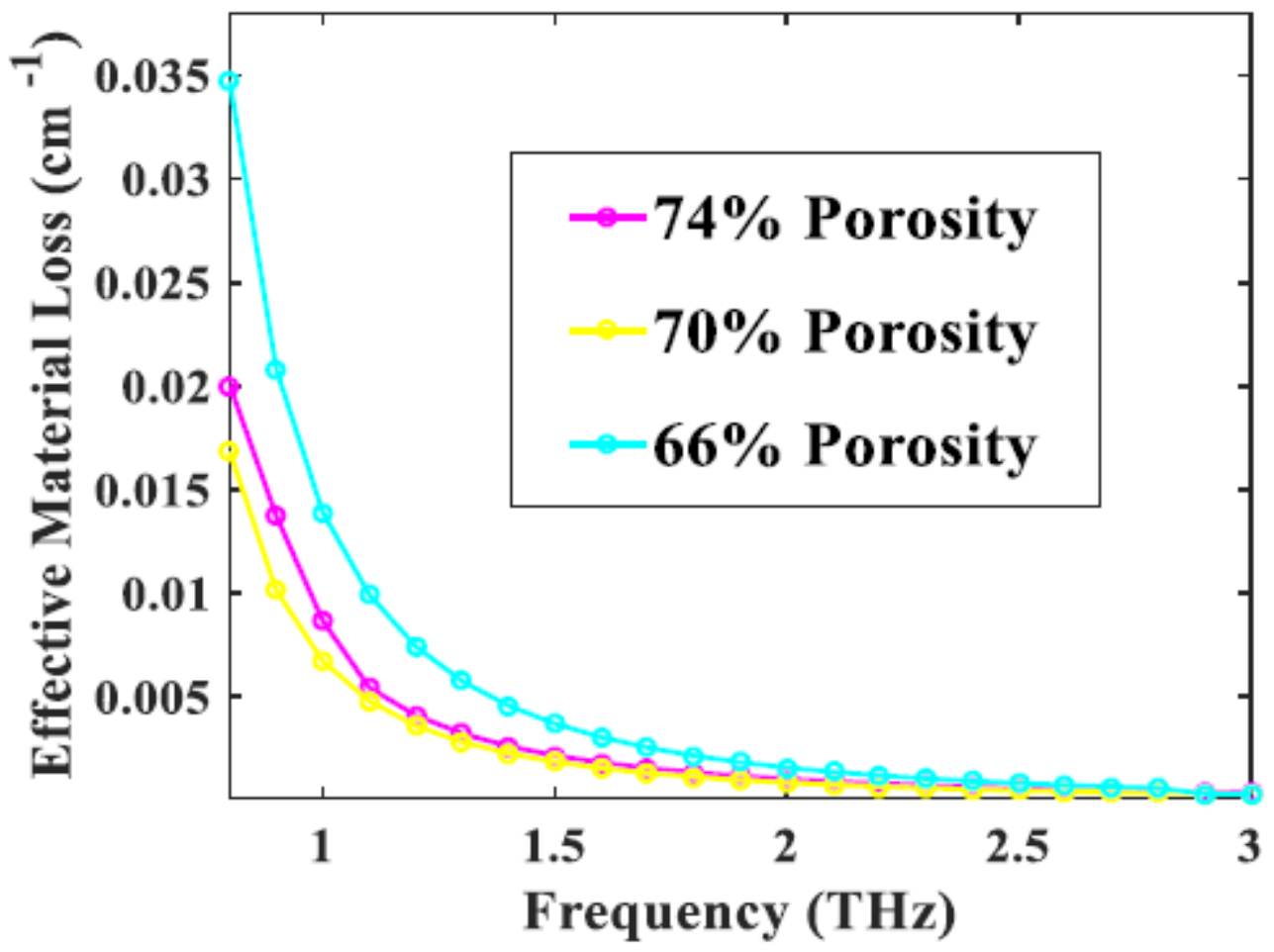

Figure 4

EML according to the frequency such as $66 \%, 70 \%$ and $74 \%$ porosities.

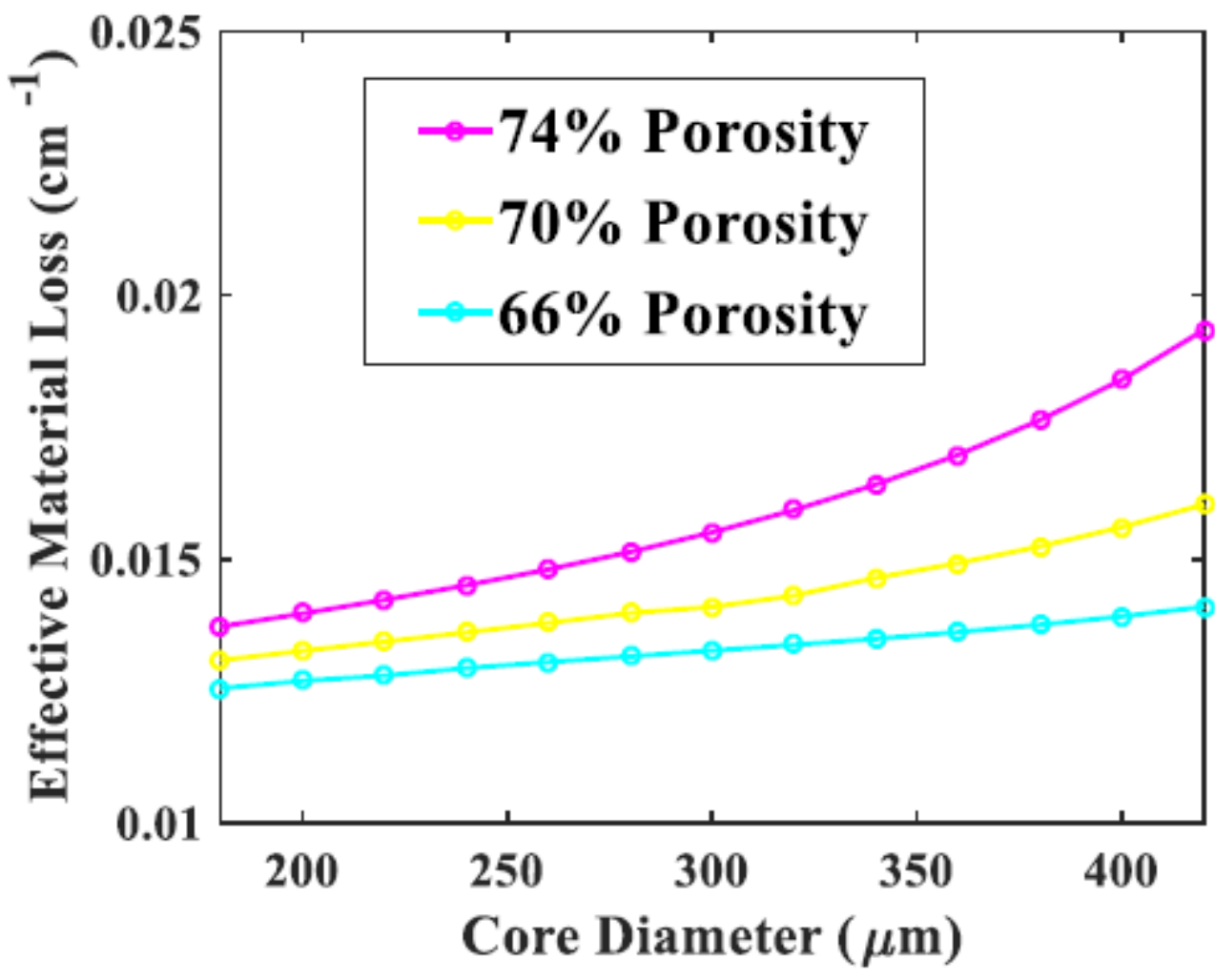

Figure 5 
EML according to the core diameters such as $66 \%, 70 \%$ and $74 \%$ porosities.

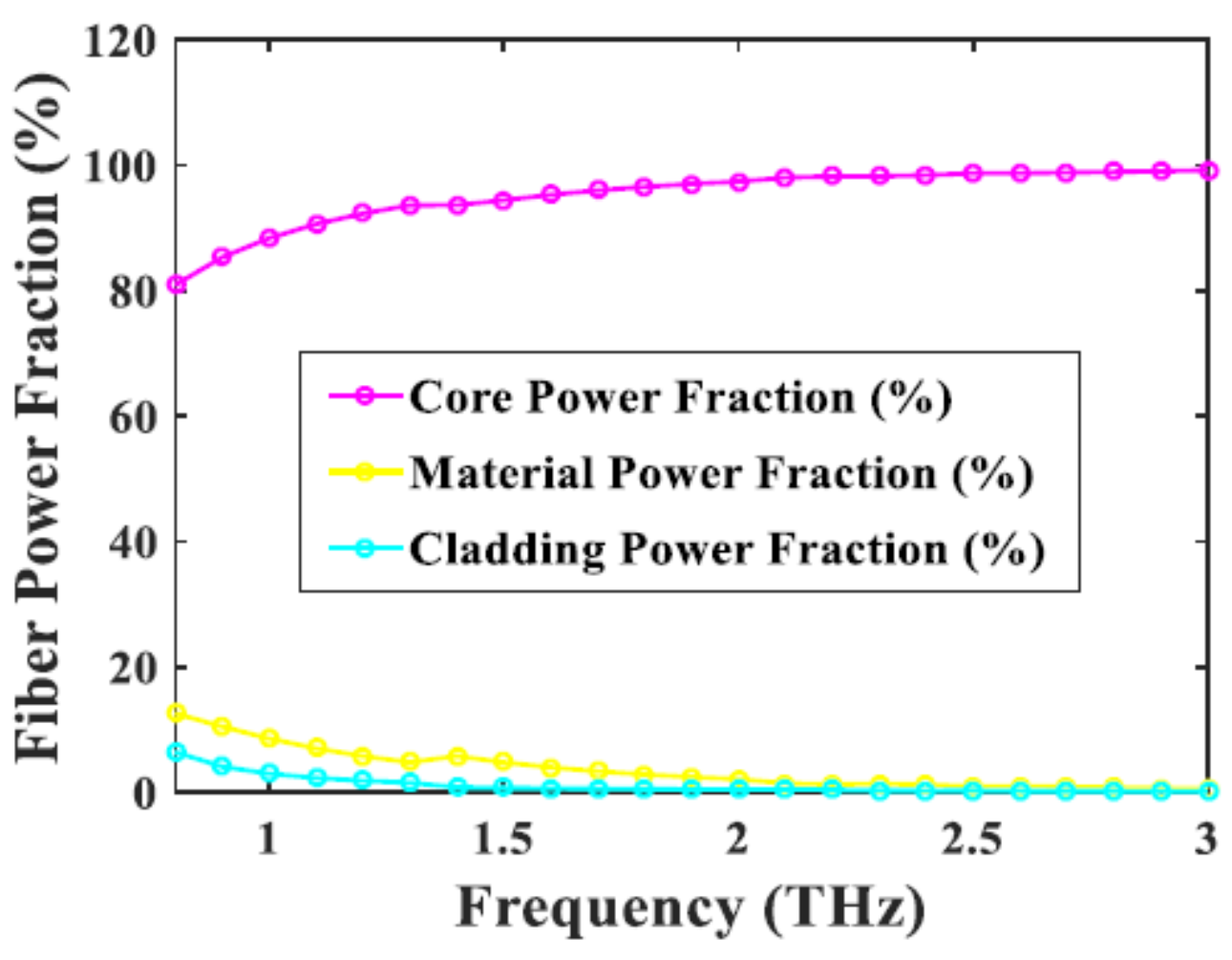

Figure 6

Power fraction according to the different frequencies for optimum constraints.

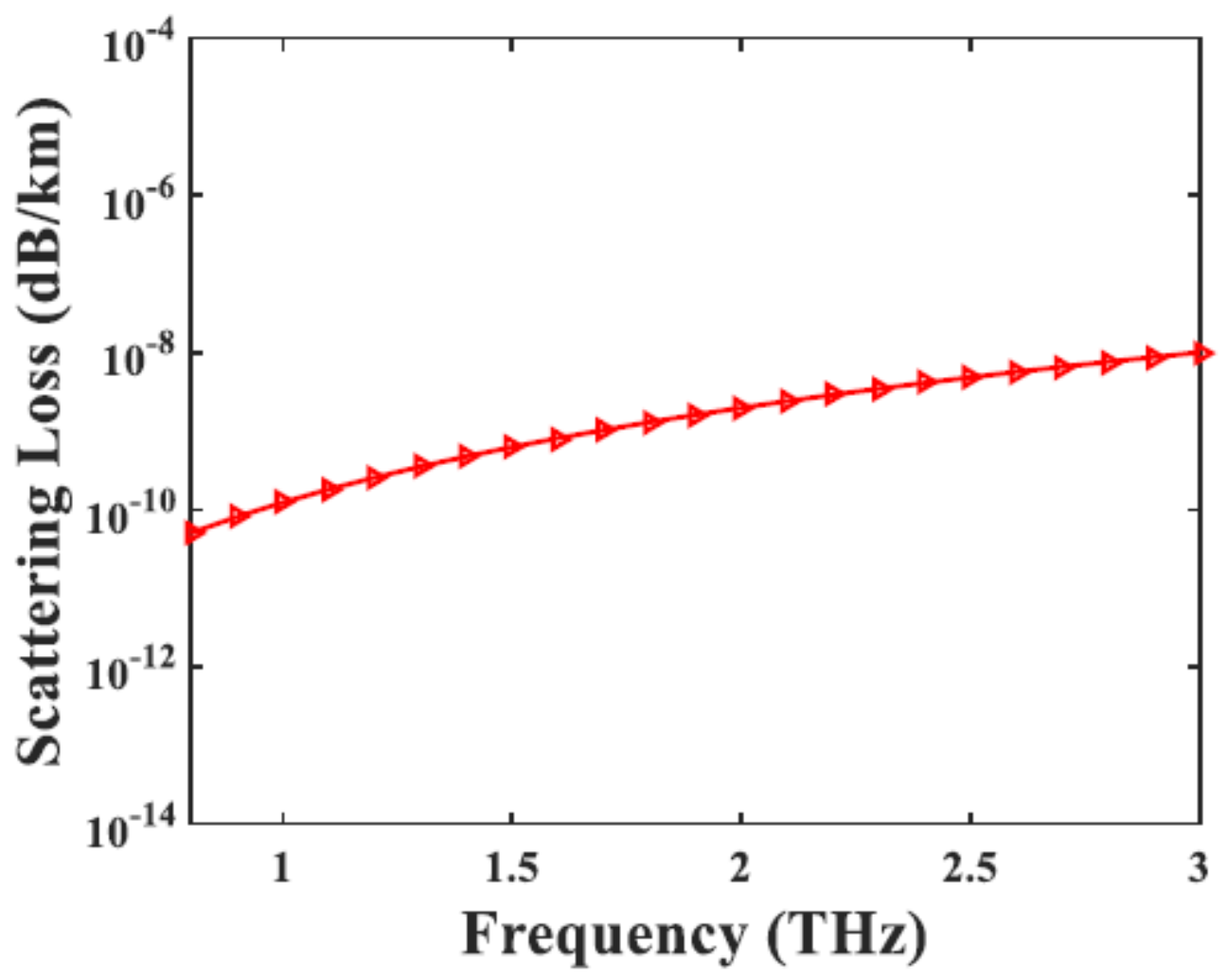

Figure 7 
Scattering loss according to the different frequencies for optimum design parameters.

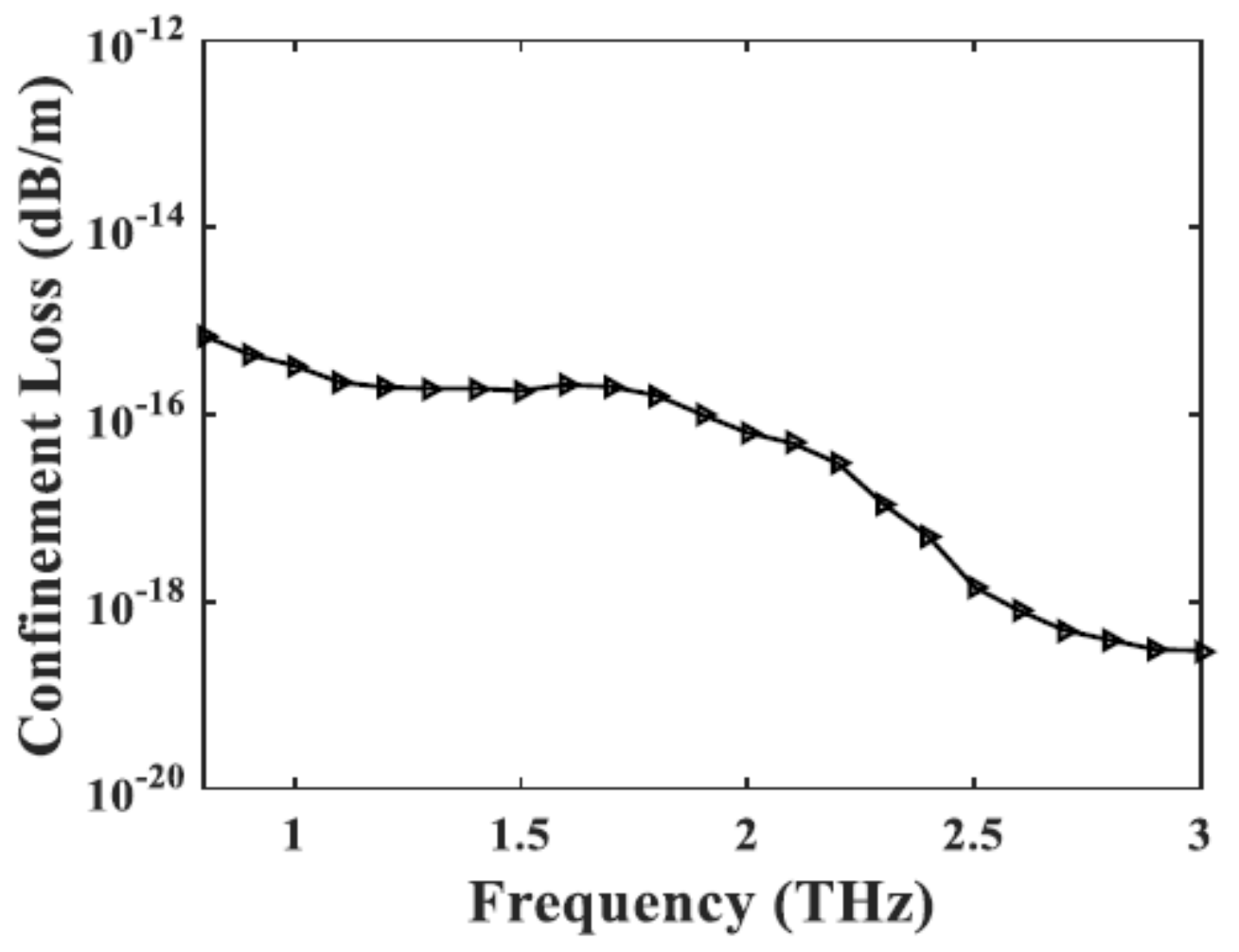

Figure 8

Confinement loss according to the different frequencies for optimum design parameters.

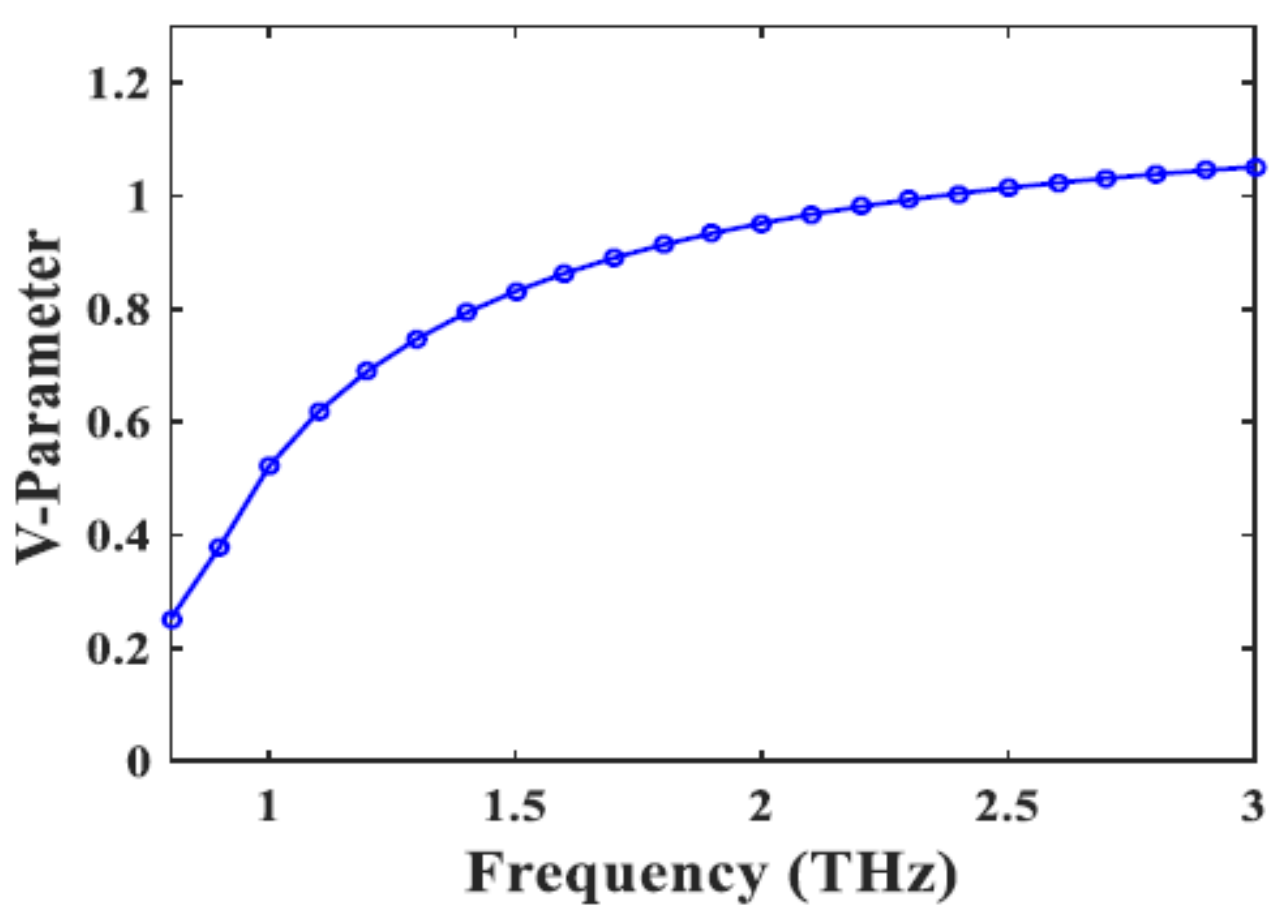

Figure 9

V-parameter according to the different frequencies for optimum design parameters. 